\title{
Photo-Induced Electron Transfer Between a Reactant Molecule and Semiconductor Photocatalyst: In Situ Doping
}

\section{$\operatorname{AUTHOR(S):~}$}

Shishido, Tetsuya; Teramura, Kentaro; Tanaka, Tsunehiro

\section{CITATION:}

Shishido, Tetsuya ... [et al]. Photo-Induced Electron Transfer Between a Reactant Molecule and Semiconductor Photocatalyst: In Situ Doping. Catalysis Surveys from Asia 2011, 15(4): 240-258

\section{ISSUE DATE:}

2011-12

URL:

http://hdl.handle.net/2433/151707

\section{RIGHT:}

The final publication is available at www.springerlink.com; This is not the published version. Please cite only the published version.; この論文 は出版社版でありません。引用の際には出版社版をご確認ご利用くだ さい。 
Title:

Photo-induced electron transfer between a reactant molecule and semiconductor photocatalyst - in situ doping

Author names and affiliation:

Tetsuya SHISHIDO, Kentaro TERAMURA, Tsunehiro TANAKA

Department of Molecular Engineering, Graduate School of Engineering, Kyoto University Katsura, Kyoto 615-8510, Japan

Running title

Electron transfer between a reactant molecule and semiconductor photocatalyst

Corresponding Author

Tsunehiro TANAKA

Tel. 81-75-383-2558 Fax. 81-75-383-2561

E-mail tanakat@moleng.kyoto-u.ac.jp

Address:

Department of Molecular Engineering, Graduate School of Engineering, Kyoto University Katsura, Kyoto 615-8510, Japan 


\begin{abstract}
The possibility of the direct electron transition between the donor/acceptor level generated by adsorbed molecules and the conduction/valence band for photo-illuminated semiconductortype metal oxide is discussed. The effective wavelength is shifted to a longer wavelength by the formation of donor/acceptor level derived from adsorbed molecule (called here "in situ doping"). This photo-activation mechanism by "in situ doping" gives us attractive ways for the removing the limit of band-gap energy, and the utilization of visible light.
\end{abstract}

Key words: in situ doping; photocatalysis; metal oxide; $\mathrm{NH}_{3}$; alcohol; amine; $\mathrm{CO}_{2}$. 


\section{Introduction}

Photocatalysis of semiconductor-type metal oxides is generally explained in terms of band theory (the classical electron transfer mechanism) accompanied by the interaction of reactants with the photo-generated electrons and holes, and is potentially available to make the catalytic reaction proceeding at low temperature. Photocatalytic reactions on a powder of semiconductor type metal oxide involves several steps as shown in Scheme 1. Electron transfer between solid and adsorbates is one of the key steps in photocatalysis. The energy transfer excluding the electron transfer clearly discriminates between photocatalysis and photosensitizing reactions. Although it may not be generally accepted, Fox and Chan [1] has proposed that the singlet oxygen species as an active oxygen species over $\mathrm{TiO}_{2}$ photocatalyst is formed by a couple of consecutive electron transfer reactions;

$$
\begin{aligned}
& \mathrm{e}^{-}+\mathrm{O}_{2} \rightarrow \mathrm{O}_{2}^{-} \\
& \mathrm{O}_{2}^{-}+\mathrm{h}^{+} \rightarrow{ }^{1} \mathrm{O}_{2}
\end{aligned}
$$

where $\mathrm{e}^{-}$and $\mathrm{h}^{+}$are the photo-generated electron and hole pair. This is clearly different from the formation of the singlet oxygen by a collision between a dye and a triplet molecular oxygen in photo-sensitizing reaction.

In 1971, Sancier and Morrison [2] found that ESR signals due to $\mathrm{O}_{2}{ }^{-}$and lattice defect (hole traps) over UV-illuminated $\mathrm{TiO}_{2}$ change drastically when illuminated in the presence of quinoline; i. e., the $\mathrm{O}_{2}{ }^{-}$signal is enhanced while defect signal disappears. They interpreted the phenomenon that a hole trapped on the defect is transferred to the adsorbed quinoline to form positively charged quinolone $\mathrm{Q}^{+}$and subsequently charge transferred complex $\mathrm{Q}^{+}-\mathrm{O}_{2}^{-}$is stabilized. Bickley et al. reported the similar phenomenon in the photooxidation of isopropanol over $\mathrm{TiO}_{2}$ that oxygen photoadsorption is promoted by pre-adsorption of isobutanol on $\mathrm{TiO}_{2}$ [3]. This shows that isopropanol is oxidized by a photoformed hole and oxygen is reduced by a photoformed electron resulting in the charge transfer via. $\mathrm{TiO}_{2}$ 
photocatalyst between adsorbed oxygen and isopropanol. In this connection, Zakharenko et al. reported $[4,5]$ that in $\mathrm{CO}$ photo-oxidation over $\mathrm{ZnO}$, adsorbed $\mathrm{O}_{2}^{-}$is formed by illumination of light with the quantum energy lower than $\mathrm{ZnO}$ band gap energy while $\mathrm{CO}$ oxidation proceeds only under illumination of light with energy higher than band gap (band-gap-illumination). This phenomenon was also examined by Murphy et al. [6] and they concluded that $\mathrm{CO}$ oxidation is dominated by the hole $\mathrm{h}^{+}$which reacts with the lattice oxygen $\mathrm{O}_{l}^{2-}$ resulting in the formation of $\mathrm{O}_{l}^{-}$expressed as follows.

$$
\mathrm{O}_{l}^{2-}+\mathrm{h}^{+} \rightarrow \mathrm{O}_{l}^{-}
$$

The same phenomenon was observed by Teichner et al. [7] in the photo-oxidation of isobutene over $\mathrm{TiO}_{2}$; i. e., adsorbed $\mathrm{O}_{2}^{-}$is formed by illumination of the light with the energy lower than $\mathrm{TiO}_{2}$ band gap energy while isobutane oxidation proceeds only under band-gap-illumination. Herein, the interesting points are the formation of adsorbed $\mathrm{O}_{2}^{-}$ radicals by illumination of the light with the lower quantum energy than band gap energy. Electrons trapped by $\mathrm{Ti}$ ions, reduced sites, seems excited to the conduction band and transferred to adsorbed oxygen to form $\mathrm{O}_{2}^{-}$. In this case, the reduced sites behave as electron donors. Thus, the photoillumination causes the band gap excitation of semiconductor-type metal oxide as well as direct excitation between donor levels and conduction band.

Here, we would like to pay attention to the direct electron transition between the donor/acceptor level generated by adsorbed molecules and the conduction/valence band and the possibility of this electron transition for photo-illuminated semiconductor-type metal oxide is discussed. The band structure of the metal oxides determines the utilizable light energy, oxidizability, and reducing ability in their photocatalysis. Therefore, a number of studies are related to the control of band structure of metal oxide [8-11]. Many researchers have been prepared the "pre-doped" or "pre-modified" photocatalysts with metals or ions to control the band structure, in other words, utilize the visible light. For example, $\mathrm{N}$-doped $\mathrm{TiO}_{2}$ 
can adsorb the visible light and shows photocatalytic activity under visible light irradiation [12-16]. On the other hand, there has been no report that the effective wavelength of photo-reaction is shifted to a longer wavelength by the formation of donor/acceptor level derived from adsorbed molecule on the catalyst during a chemical reaction. Here, we shall call this type of photocatalyst modification "in situ doping". We demonstrate that a redshift of effective wavelength due to the direct electron transition bewteen the donor/acceptor level derived from adsorbed molecule and the conduction/valence band in the following three types of reactions; the photo-SCR on $\mathrm{TiO}_{2}$ with $\mathrm{NH}_{3}$ in the presence of $\mathrm{O}_{2}$ (photo-SCR), the photo-oxidation of alcohols or imines on $\mathrm{Nb}_{2} \mathrm{O}_{5}$ with $\mathrm{O}_{2}$, and the photo-reduction of $\mathrm{CO}_{2}$ with $\mathrm{H}_{2}$ or $\mathrm{CH}_{4}$ on $\mathrm{MgO}$ or $\mathrm{ZrO}_{2}$.

\section{The donor level generated by adsorbed molecule}

2.1. Photo-activation of adsorbed $\mathrm{NH}_{3}$ on $\mathrm{TiO}_{2}$ : Photoassisted Selective Catalytic Reduction (photo-SCR) with $\mathrm{NH}_{3}$

\subsubsection{SCR with $\mathrm{NH}_{3}$}

NOx is one of the environmental pollutants and causes acid rain and photochemical smog. Therefore, it is desirable to remove $\mathrm{NO} x(\mathrm{de}-\mathrm{NO} x)$ in the stationary emission source and the mobile emission source. In the stationary emission source, NOx is conventionally removed from the exhaust gas by the selective catalytic reduction system with $\mathrm{NH}_{3}$ as a reductant $\left(\mathrm{NH}_{3}-\mathrm{SCR}\right)$ in the presence of the excess $\mathrm{O}_{2}\left(4 \mathrm{NO}+4 \mathrm{NH}_{3}+\mathrm{O}_{2} \rightarrow 4 \mathrm{~N}_{2}+6 \mathrm{H}_{2} \mathrm{O}\right)$ over $\mathrm{V}_{2} \mathrm{O}_{5}$-based catalysts such as $\mathrm{V}_{2} \mathrm{O}_{5}-\mathrm{WO}_{3}\left(\right.$ or $\left.\mathrm{V}_{2} \mathrm{O}_{5}-\mathrm{MoO}_{3}\right) / \mathrm{TiO}_{2}$ [17-20]. This system shows high NO conversion (99\%), high $\mathrm{N}_{2}$ selectivity (> 90\%) and resistance for $\mathrm{H}_{2} \mathrm{O}$ and $\mathrm{SO} x$, although the catalyst requires high operating temperature $(573-673 \mathrm{~K})$ [21]. Since the $\mathrm{NH}_{3}$-SCR system is often located downstream of the de-SO $x$, de-halogen and dust collection systems to inhibit deactivation of catalyst, the inlet temperature of the exhaust gas in the 
$\mathrm{NH}_{3}$-SCR system falls below $453 \mathrm{~K}$. Consequently, it is necessary to re-heat the catalysis bed and the gas up to the operating temperature of the catalyst. Therefore, it is desired to develop a new de-NO $x$ system working at low temperature $(<453 \mathrm{~K})$.

Since $\mathrm{NH}_{3}$ is quite stable, the activation of $\mathrm{NH}_{3}$ seems to be key step in the low-temperature $\mathrm{NH}_{3}-\mathrm{SCR}$ and $\mathrm{SCO}$ systems. Recently, we found that $\mathrm{TiO}_{2}$ can activate $\mathrm{NH}_{3}$ at low temperature and acts as an effective catalyst for both photo-SCR with $\mathrm{NH}_{3}$ and photo-SCO [22-34]. We have clarified the activation mechanism of adsorbed $\mathrm{NH}_{3}$ on $\mathrm{TiO}_{2}$ and found that the direct electorn trnasfer from donor level derived form adsorbed amido $\left(\mathrm{NH}_{2}\right)$ species to the conduction band of $\mathrm{TiO}_{2}$ was involved in the activation mechanism of adsorbed $\mathrm{NH}_{3}$ on $\mathrm{TiO}_{2}$.

\subsubsection{Photo-SCR with $\mathrm{NH}_{3}$ onTiO$_{2}$}

Figure 1 shows the time course of $\mathrm{N}_{2}$ evolution rate of photo-SCR. NO conversion and $\mathrm{N}_{2}$ selectivity attained to $100 \%$ and $96 \%$ respectively in the conventional fixed bed flow system $\left(\mathrm{GHSV}=8,000 \mathrm{~h}^{-1}\right)$. The $\mathrm{N}_{2}$ evolution rate gradually increased at the initial stage and reached a steady rate at $1.5 \mathrm{~h}$. However, when the reaction gas (a mixture of $\mathrm{NO} / \mathrm{NH}_{3} / \mathrm{O}_{2}$ ) was passed in the dark for $0.5 \mathrm{~h}$, and then photo-irradiation was started, the $\mathrm{N}_{2}$ evolution rate immediately jumped to the level of the steady rate $[23,27]$. This clearly indicates that the induction period was the time for saturation of the adsorption equilibrium of the reactant molecule. When $\mathrm{NH}_{3}$ were passed for $1.5 \mathrm{~h}$ in the dark, then the gas was switched to a mixture of $\mathrm{NO} / \mathrm{O}_{2}$ and the photo-irradiation was started, $\mathrm{N}_{2}$ was evolved. The $\mathrm{N}_{2}$ evolution rate gradually decreased and the total amount of evolved $\mathrm{N}_{2}$ was consistent with that of equilibrium adsorption of $\mathrm{NH}_{3}$ on $\mathrm{TiO}_{2}$. On the contrary, when a mixture of $\mathrm{NO} / \mathrm{O}_{2}$ was firstly passed and then switched to $\mathrm{NH}_{3}$, neither $\mathrm{N}_{2}$ nor $\mathrm{N}_{2} \mathrm{O}$ was formed. These results suggest that $\mathrm{NH}_{3}$ species adsorbed on Lewis acid site is excited by photo-irradiation and reacts with NO in the gas phase to produce $\mathrm{N}_{2}$. 
Furthermore, this is supported by the fact that only ${ }^{15} \mathrm{~N}^{14} \mathrm{~N}$ was evolved in the photo-SCR of ${ }^{15} \mathrm{NO}$ with ${ }^{14} \mathrm{NH}_{3}$ in the presence of $\mathrm{O}_{2}[24,35]$.

\subsubsection{Action spectrum of photo-SCR with $\mathrm{NH}_{3}$ on $\mathrm{TiO}_{2}$}

Figure 2 shows the apparent quantum efficiency of the photo-SCR over $\mathrm{TiO}_{2}$ as a function of the incident light (action spectrum) and a UV-Vis spectrum of $\mathrm{TiO}_{2}$. The band gap of this $\mathrm{TiO}_{2}$ was estimated to $3.28 \mathrm{eV}$ (photo-excitation energy is $385 \mathrm{~nm}$ ). The action spectrum is in good agreement with the UV-Vis spectrum of $\mathrm{TiO}_{2}$ in the region of wavelength $<385 \mathrm{~nm}$, where the holes and electrons generated by the bad gap excitation of $\mathrm{TiO}_{2}$ are the driving force in the photo-SCR reaction. On the other hand, above $385 \mathrm{~nm}$, the action spectrum exhibited a different behavior from that of the UV-vis spectrum. Photo-SCR proceeded under irradiation up to ca. $450 \mathrm{~nm}(2.76 \mathrm{eV})$, although the band gap of this $\mathrm{TiO}_{2}$ was estimated to $3.28 \mathrm{eV}$. The feature of this action spectrum is analogous to the UV-Vis spectrum of N-doped $\mathrm{TiO}_{2}[12,13,36]$. It seems that the electron transfer from $\mathrm{N} 2 \mathrm{p}$ of adsorbed $\mathrm{NH}_{3}$ to $\mathrm{Ti} 3 \mathrm{~d}$ directly took place in this region. It is thought that the doping effect, such as nitrogen-doped $\mathrm{TiO}_{2}$, would occur in the case of $\mathrm{TiO}_{2}$ surface with adsorbed $\mathrm{NH}_{3}$ in the photo-SCR in the wavelength region above $385 \mathrm{~nm}$.

\subsubsection{Photo-activation mechanism of $\mathrm{NH}_{3}$ on $\mathrm{TiO}_{2}$}

The adsorbed species and intermediates of photo-SCR were identified by in situ FT/IR spectra (Fig. 3). After $\mathrm{NH}_{3}$ adsorbed on $\mathrm{TiO}_{2}$, the bands $\left(1136,1215\right.$, and $1599 \mathrm{~cm}^{-1}$ ) due to adsorbed $\mathrm{NH}_{3}$ species on Lewis acid site of $\mathrm{TiO}_{2}$ appeared [37-39]. The bands at 1599 and $1215 \mathrm{~cm}^{-1}$ retained their intensity after evacuation (Fig. 3 (b)) and exposure to NO in the dark (Fig. 3 (c)). The intensity of the bands due to adsorbed $\mathrm{NH}_{3}$ decreased gradually with irradiation time. On the other hand, the band at $1624 \mathrm{~cm}^{-1}$, which is assignable to the 
deformation vibration of $\mathrm{H}_{2} \mathrm{O}$ [40], grew. Furthermore, new bands between 1400 and 1600 $\mathrm{cm}^{-1}$ were observed and then disappeared. These new bands are assigned to the nitrosamide species $\left(\mathrm{NH}_{2} \mathrm{NO}\right)$ by comparing the FT/IR spectrum of $\mathrm{TiO}_{2}$ exposed with ${ }^{14} \mathrm{NO}$ and $\mathrm{NH}_{3}$ to that exposed with ${ }^{15} \mathrm{NO}$ and $\mathrm{NH}_{3}[24,35]$. These results indicate that the intermediate of photo-SCR is the nitrosamide species and the nitrosamide species is decomposed to $\mathrm{N}_{2}$ and $\mathrm{H}_{2} \mathrm{O}$. Moreover, it was confirmed that the $\mathrm{Ti}^{3+}$ species of $\mathrm{TiO}_{2}$ reduced by $\mathrm{H}_{2}$ was re-oxidized to the $\mathrm{Ti}^{4+}$ species by exposure to $\mathrm{O}_{2}$ easily even at room temperature using UV-Vis spectroscopy [31].

Figure 4 shows the ESR spectra of $\mathrm{TiO}_{2}$. After evacuation at $673 \mathrm{~K}$, the signals are derived from the $\mathrm{Ti}^{3+}$ species (Fig. 4 (a)) [41-44]. There is little change in ESR signal by the exposure of $\mathrm{NH}_{3}$ to $\mathrm{TiO}_{2}$ in the dark. On the other hand, ESR signal changed drastically after photo-irradiation. New signals assignable to $\mathrm{NH}_{2}$ radical [45-48] were detected together with signals assigned to $\mathrm{Ti}^{3+}$. These new signals were quite stable even after more than 1 hour at $123 \mathrm{~K}$ without photo-irradiation. The half-life of charge-separated state of $\mathrm{TiO}_{2}$ was estimated to be below 100 ps $[49,50]$. It is widely thought that the photo-generated electrons and holes are consumed by recombination much more rapidly than by the photocatalytic reaction and the recombination is the main reason of too short lifetime of the charge-separated state and resulting in low activity of $\mathrm{TiO}_{2}$. On the other hand, the half-life of $\mathrm{NH}_{2}$ radical on $\mathrm{TiO}_{2}$ at reaction temperature of photo-SCR $(323 \mathrm{~K})$ was calculated to be $1.4 \mathrm{~min}$ [31]. This suggests that the holes were trapped by $\mathrm{NH}_{2}$ radical and recombination of the photo-generated electrons and holes was inhibited. However, these signals immediately disaapeared by the exposure to $\mathrm{NO}$ in the dark whereas the intensity of signals due to $\mathrm{Ti}^{3+}$ species increased. Based on these results, we concluded that 1 ) the photo-generated electron is trapped on $\mathrm{Ti}^{4+}$ to form $\mathrm{Ti}^{3+}$ and positive hole is captured by adsorbed $\mathrm{NH}_{3}$ species to convert to active $\mathrm{NH}_{2}$ radical, and that 2) $\mathrm{NO}$ in the gas phase attacks the $\mathrm{NH}_{2}$ radical on $\mathrm{TiO}_{2}$ rapidly. As both $\mathrm{NH}_{2}$ 
radical and $\mathrm{NO}$ are doublet state species, it follows that $\mathrm{NH}_{2}$ radical reacts with $\mathrm{NO}$ easily without irradiation. Moreover, the formation of a $\mathrm{NH}_{2} \mathrm{NO}$ intermediate was confirmed by FT/IR spectroscopy after admittance of $\mathrm{NO}$ to $\mathrm{TiO}_{2}$ adsorbing $\mathrm{NH}_{3}$ under photo-irradiation. As described above, the intensity of signals due to $\mathrm{Ti}^{3+}$ species increased after the introduction of NO. It seems that the electron transfer took place from the $\mathrm{N}$ atom of adsorbed $\mathrm{NH}_{3}$ to the $\mathrm{Ti}$ atom of $\mathrm{TiO}_{2}$ bulk. In other words, the photo-generated electron was trapped on $\mathrm{Ti}$ atom and the photo-generated hole was captured by the $\mathrm{NH}_{2}^{-}$species derived from adsorbed $\mathrm{NH}_{3}$. As a result, the $\mathrm{NH}_{2}^{-}$species converted to the active $\mathrm{NH}_{2}$ radical. On the other hand, the electron may move into inside of $\mathrm{TiO}_{2}$ bulk as a stable free electron. Before the exposure to NO, recombination took place between a part of $\mathrm{Ti}^{3+}$ species and the $\mathrm{NH}_{2}$ radical. On the other hand, after the exposure to NO, the electron could not recombine because of losing an opponent $\left(\mathrm{NH}_{2}\right.$ radical). The electron was localized and stabilized in inside of $\mathrm{TiO}_{2}$, and the signals assigned to the $\mathrm{Ti}^{3+}$ species increased in intensity.

On the basis of these results, we proposed Eley-Rideal type mechanism as follows (Scheme 2) $[24,27,28,31,34]$; 1) the $\mathrm{NH}_{3}$ adsorbs on Lewis acid site of $\mathrm{TiO}_{2}, 2$ ) the adsorbed $\mathrm{NH}_{3}$ species is excited by photo-irradiation, 3$)$ the excited species $\left(\mathrm{NH}_{2}\right.$ radical) reacts with $\mathrm{NO}$ in the gas phase to form the nitrosamide species $\left.\left(\mathrm{NH}_{2} \mathrm{NO}\right), 4\right)$ the nitrosamide species is decomposed to $\mathrm{N}_{2}$ and $\mathrm{H}_{2} \mathrm{O}$, and 5) $\mathrm{Ti}^{3+}$ site is re-oxidized by molecular oxygen.

\subsubsection{Generation of donor level derived from $\mathrm{NH}_{3}$ adsorbed on $\mathrm{TiO}_{2}$}

Action spectrum of photo-SCR with $\mathrm{NH}_{3}$ on $\mathrm{TiO}_{2}$ (Fig. 2) indicates that the mechanism of the $\mathrm{NH}_{2}$ radical formation at wavelength $<385 \mathrm{~nm}$ is different from that at $>385 \mathrm{~nm}$. To reveal whether a new energy level derived from adsorbed $\mathrm{NH}_{3}$ on $\mathrm{TiO}_{2}$ is located between the valence band (HOMO) and the conduction band (LUMO) of $\mathrm{TiO}_{2}$ or not, density functional theory (DFT) calculations were employed [31]. Figure 5 shows the model for dissociative 
adsorption of $\mathrm{NH}_{3}$ on the $\mathrm{Ti}_{7} \mathrm{O}_{27} \mathrm{H}_{26}$ cluster model for the $\mathrm{TiO}_{2}$ (101) anatase surface. The energy levels of the molecular orbitals around HOMO and LUMO for this model are shown in Fig. 6. We confirmed that occupied and virtual orbitals around HOMO and LUMO of the $\mathrm{Ti}_{7} \mathrm{O}_{27} \mathrm{H}_{26}$ cluster (before adsorption of $\mathrm{NH}_{3}$ ) consist of $\mathrm{O} 2 \mathrm{p}$ and $\mathrm{Ti} 3 \mathrm{~d}$ orbitals, respectively. Figure 7 shows selected molecular orbitals. The $\mathrm{Ti}_{7} \mathrm{O}_{27} \mathrm{H}_{26}$ model cluster with dissociative adsorbed $\mathrm{NH}_{3}$ exhibited quite different electronic state from the $\mathrm{Ti}_{7} \mathrm{O}_{27} \mathrm{H}_{26}$ model cluster. HOMO of the $\mathrm{Ti}_{7} \mathrm{O}_{27} \mathrm{H}_{26}$ model cluster with dissociative adsorbed $\mathrm{NH}_{3}$ consists of $\mathrm{N} 2 \mathrm{p}$ orbital of $\mathrm{NH}_{2}$. This result clearly indicates that $\mathrm{N} 2 \mathrm{p}$ electron donor level is located between $\mathrm{O} 2 \mathrm{p}$ and $\mathrm{Ti} 3 \mathrm{~d}$ when $\mathrm{NH}_{2}$ species are formed on a $\mathrm{TiO}_{2}$ surface by the dissociatively-adsorption of $\mathrm{NH}_{3}$. Indeed, the ESR signal of $\mathrm{NH}_{2}$ radical was obtained under visible light irradiation $(\lambda>400 \mathrm{~nm}$, Y-43 cutoff filter used), although the ESR signal intensity was lower than under UV irradiation $(\lambda>300 \mathrm{~nm})$. Apparently non-dissociatively adsorbed $\mathrm{NH}_{3}$ had liittle influence the electronic states of $\mathrm{Ti}_{7} \mathrm{O}_{27} \mathrm{H}_{26}$, for example, the molecular orbitals of $\mathrm{HOMO}, \mathrm{HOMO}-1$ and LUMO in the $\mathrm{Ti}_{7} \mathrm{O}_{27} \mathrm{H}_{26}$ cluster closely resemble to those in the $\mathrm{NH}_{3}$-adsorbed one. This result indicates that the electron transfer occurs from $\mathrm{O} 2 \mathrm{p}$ to Ti $3 \mathrm{~d}$ regardless of the adsorption of $\mathrm{NH}_{3}$.

Based on these results, we conclude that the photo-activation of $\mathrm{NH}_{3}$ adsorbed on $\mathrm{TiO}_{2}$ to $\mathrm{NH}_{2}$ radical occurs through two paths as shown in Scheme 3. One is the electron transition from the valence band consisting of $\mathrm{O} 2 \mathrm{p}$ orbitals to the conduction band consisting of $\mathrm{Ti} 3 \mathrm{~d}$ orbitals of $\mathrm{TiO}_{2}$. This electron transition mainly takes place in the region of the wavelength $<385 \mathrm{~nm}$. The other is the direct electron transfer from $\mathrm{N} 2 \mathrm{p}$ of adsorbed $\mathrm{NH}_{3}$ to Ti $3 \mathrm{~d}$. This $\mathrm{N}$ $2 p$ electron donor level formed between $\mathrm{O} 2 \mathrm{p}$ and $\mathrm{Ti} 3 \mathrm{~d}$ enables the photo-SCR to proceed even under visible light irradiation $(400-450 \mathrm{~nm})$, in other words, a lower energy than the band gap energy of $\mathrm{TiO}_{2}$. It can be thought that the expansion of the effective wavelength of $\mathrm{TiO}_{2}$ by adsorption of $\mathrm{NH}_{3}$, called here, "in situ doping", is one of the factors for high activity 
of $\mathrm{TiO}_{2}$ in the photo-SCR.

\subsection{Photo-activation of alcohols and amines on $\mathrm{Nb}_{2} \mathrm{O}_{5}$}

\subsubsection{Photo oxidation of alcohols and amines with molecular oxygen}

Catalytic alcohol oxidation to carbonyl compounds is one of the most important chemical transformations used in the industrial chemistry and in organic syntheses [51-53]. Oxidation of amines to imines is also an important chemical transformation because of the versatile applications of imines as synthetic intermediates of medicines and biologically active nitrogen containing organic compounds [54]. Several oxidation procedures with stoichiometric, toxic, corrosive and expensive oxidants have been reported [51-58]. However, a catalytic system using molecular oxygen as a sole oxidant has been desired [55, 59-64].

In this respect, photocatalytic oxidation with molecular oxygen has been receiving noticeable attention. $\mathrm{TiO}_{2}$ has been identified as one example of a practical and useful photocatalysts [65-68], and widely used in degradation of organic pollutants in air and water. However, in the most part of these reports, $\mathrm{TiO}_{2}$ is used in vapor phase oxidations at high temperature, oxidation of only lower alcohols, and a low selectivity to partial oxidized products due to excess photo-activation of target products which leads to deep oxidation. Zhao et al. [69, 70] reported that the photooxidation of alcohols on $\mathrm{TiO}_{2}$ could be dramatically accelerated without any loss of selectivity by adsorption of Brønsted acid and this effect by Brønsted acid results from the decomposition of the relatively stable side-on peroxide promoted by the protons, which effectively clean the catalytic $\mathrm{Ti}-\mathrm{OH}_{2}$ sites. However, this system requires the use of benzotrifluoride as a solvent. They also reported that photooxidation of amines on $\mathrm{TiO}_{2}$ under UV irradiation gave a high selectivity to imines under a diluted conditions (e.g. $10 \mathrm{mg}$ of catalyst, $0.1 \mathrm{mmol}$ of amine, and $5 \mathrm{ml}$ of solvent) [71]. $\mathrm{Su}$ and co-workers reported that mesoporous graphite carbon nitride $\left(\mathrm{mpg}-\mathrm{C}_{3} \mathrm{~N}_{4}\right)$ can 
work as effective photocatalysts for the selective oxidations of benzylic alcohols and amines with visible light $[72,73]$. Although $m p g-\mathrm{C}_{3} \mathrm{~N}_{4}$ exhibits excellent catalytic performance under visible light irradiation, high pressure of oxygen $(>0.5 \mathrm{MPa})$ and benzotrifluoride as a solvent are required to give a good yield. Shiraishi and co-workers reported that $\mathrm{TiO}_{2}$ partially covered with $\mathrm{WO}_{3}$ showed activity for the photooxidation of alcohols in water with molecular oxygen under irradiation at $\lambda>350 \mathrm{~nm}$ [74]. In the case of photooxidaiton of benzylalcohol, the selectivity to benzaldehyde reached at $56 \%$ at $50 \%$ of alcohol conversion under diluted condition ( $5 \mathrm{mg}$ of catalysts, $0.1 \mathrm{mmol}$ of benzylalcohol, $5 \mathrm{~mL}$ of water as a solvent).

\subsubsection{Photo-oxidation of alcohols and amines with molecular oxygen on $\mathrm{Nb}_{2} \mathrm{O}_{5}$}

Recently, we found the photo-oxidation of alcohols to carbonyl compounds selectively proceeds over $\mathrm{Nb}_{2} \mathrm{O}_{5}$ at low temperature without organic solvents and without any additives [75-78]. Various metal oxides $\left(\mathrm{SiO}_{2}, \mathrm{MgO}, \mathrm{Al}_{2} \mathrm{O}_{3}, \mathrm{ZrO}_{2}, \mathrm{~V}_{2} \mathrm{O}_{5}, \mathrm{Ta}_{2} \mathrm{O}_{5}, \mathrm{MoO}_{3}\right.$, and $\left.\mathrm{WO}_{3}\right)$ showed no activity and the activity of $\mathrm{ZnO}$ was very low. $\mathrm{TiO}_{2}$ showed higher activity than $\mathrm{Nb}_{2} \mathrm{O}_{5}$, however, the $\mathrm{Nb}_{2} \mathrm{O}_{5}$ catalyst showed higher selectivity than $\mathrm{TiO}_{2}$ at the same conversion level, indicating that $\mathrm{Nb}_{2} \mathrm{O}_{5}$ is suitable for selective oxidation. The photo-oxidation did not take place in the dark. Autooxidation proceeded when 1-phenylethanol, cyclohexanol and benzylalcohol were irradiated without catalyst. This was due to the formation of radical species by the photo-decomposition of carbonyl compounds (Norrish Type I reaction) which were present as impurities in the alcohols. $\mathrm{Nb}_{2} \mathrm{O}_{5}$ catalyst improved the conversions and/or selectivities to carbonyl compounds greatly. The less reactive primary alcohol, 1-pentanol was also photooxidized selectively by using $\mathrm{Nb}_{2} \mathrm{O}_{5}$ catalyst. The $\mathrm{Nb}_{2} \mathrm{O}_{5}$ catalyst was reusable and showed the same conversion and selectivity without any pretreatment as the catalyst as prepared.

The oxidation of various amines including primary, secondary and bicycloamine derivatives 
were examined by using the $\mathrm{Nb}_{2} \mathrm{O}_{5}$ photocatalyst (Table 1) [79]. Primary benzylamine derivatives bearing various functional groups $\left(\mathrm{OMe}, \mathrm{Me}, \mathrm{H}, \mathrm{Cl}\right.$ and $\left.\mathrm{CF}_{3}\right)$ were converted to corresponding coupled imines with excellent yields (entries 1-7). A primary aliphatic amine was also converted to correspoding coupled imine, but the selectivity was lower than those of benzylic homologues (entry 8 ). Secondary $N$-alkylbenzylamines (alkyl $=\mathrm{Bn}, \mathrm{Ph}, i \mathrm{Pr}$ and $t \mathrm{Bu}$ ) were also oxidized to dehydrogenated imines. (entries 9-12). Relative high yields were observed in the oxidations of $N$-isopropylbenzylamine and dibenzylamine. On the other hand, $\mathrm{N}$-phenyl and $\mathrm{N}$-tert-butyl derivatives were oxidized very slowly. Benzaldehyde was formed as a by-product in the oxidations of these secondary benzylic amines. The formation of benzaldehyde is attributed to the oxidative cleavage of the $\mathrm{C}-\mathrm{N}$ bond. In addition, a small amount of $N$-benzylidene benzylamine was also yielded in these cases. This represents an involvement of the $\mathrm{C}-\mathrm{N}$ bond cleavage, followed by coupling of the fragments. 1,2,3,4-tetrahydroisoquinoline was smoothly converted to mono-dehydrogenated 3,4-dihidroisoquinoline with high yield (entry 13). In contrast, the rate of oxidation of 1,2,3,4-tetrahidroquinoline to aromatized quinoline was much slower than the iso-isomer (entry 14). In this case, a small amount of mono-dehydrogenated 3,4-dihidroquinoline as an intermediate product was also detected. The significant difference of the reaction rate between the tetrahydroquinoline isomers is generally observed in various catalytic systems [73, 80-82]. Indole was yielded with moderate selectivity in the oxidation of indoline. The $\mathrm{Nb}_{2} \mathrm{O}_{5}$ photocatalyst was reusable and showed the same conversion and selectivity of fresh catalyst without any pretreatment as well as photooxidation of alcohol. The amine oxidations over $\mathrm{Nb}_{2} \mathrm{O}_{5}$ took place even under visible light (> $390 \mathrm{~nm}$ ) irradiation (entries 1' $-15^{\prime}$ ). Although the reaction rates were lower than that under UV (> $300 \mathrm{~nm}$ ) irradiation, comparable selectivities were obtained. In the absence of $\mathrm{Nb}_{2} \mathrm{O}_{5}$, oxidation of benzylamine did not proceed under visible irradiation (entry 1 '). 


\subsubsection{Action spectrum of photooxidation of alcohol on $\mathrm{Nb}_{2} \mathrm{O}_{5}$}

Figure 8 shows the apparent quantum efficiency of photo-xidation of 1-pentanol as a function of the wavelength of the incident light (action spectrum) and a UV-Vis spectrum of $\mathrm{Nb}_{2} \mathrm{O}_{5} . \mathrm{Nb}_{2} \mathrm{O}_{5}$ exhibited an intense absorption band aroud $275 \mathrm{~nm}$ corresponding to the interband transition (from valence band to conduction band) of $\mathrm{Nb}_{2} \mathrm{O}_{5}$. Although band gap of $\mathrm{Nb}_{2} \mathrm{O}_{5}$ was estimated as about $3.2 \mathrm{eV}$ (for a photoexcitation wavelength of $390 \mathrm{~nm}$ ), the photo-oixdation of 1-pentanol took place under irradiation up to ca. $480 \mathrm{~nm}$. A red shift of the effective wavelength is similar to that of photo-SCR over $\mathrm{TiO}_{2}$. A slight increase in absorption around 300-350 nm was observed by adsorption of 1-pentanol on $\mathrm{Nb}_{2} \mathrm{O}_{5}$. The difference spectrum before and after the absorption of 1-penatnol showed an absorption band at $340 \mathrm{~nm}$. It is reported that 1-pentanol had no absorption at wavelength longer than $300 \mathrm{~nm}$. Therefore, this band around $340 \mathrm{~nm}$ would be attributed to absorption of a surface complex consisting of adsorbed alcohol and $\mathrm{Nb}_{2} \mathrm{O}_{5}$. The action spectrum of the photo-oxidation of 1-pentanol on $\mathrm{Nb}_{2} \mathrm{O}_{5}$ showed a good correlation with the difference spectrum, suggesting that the photo-oxidation of alcohol was triggered by light absorption of the surface complex consisting of adsorbed alcohol and $\mathrm{Nb}_{2} \mathrm{O}_{5}$.

A red shift of the effective wavelength was also observed in the photo-oxidation of benzylamine over $\mathrm{Nb}_{2} \mathrm{O}_{5}$ [79]. The photo-oixdation of benzylamine took place under irradiation up to ca. $460 \mathrm{~nm}$. The difference spectrum before and after the absorption of benzylamine showed an absorption band at $350 \mathrm{~nm}$. Since benzylamine has no absorption at wavelength longer than $300 \mathrm{~nm}$, this band around $350 \mathrm{~nm}$ would be attributed to absorption of a surface complex consisting of adsorbed amine and $\mathrm{Nb}_{2} \mathrm{O}_{5}$. This result strongly suggests that the photo-oxidation of amine was also triggered by light absorption of the surface complex consisting of adsorbed amine and $\mathrm{Nb}_{2} \mathrm{O}_{5}$. 


\subsubsection{Mechanism of photo-oxidation of alcohols on $\mathrm{Nb}_{2} \mathrm{O}_{5}$}

The adsorbed species and intermediates of photo-oxidation were identified by in situ FT/IR spectra of adsorbed cyclohexanol on $\mathrm{Nb}_{2} \mathrm{O}_{5}$. Figure 9 shows the FT/IR spectra of adsorbed cyclohexanol on $\mathrm{Nb}_{2} \mathrm{O}_{5}$. The bands at 1467 and $1452 \mathrm{~cm}^{-1}$ were assigned to $\delta_{\mathrm{s}}\left(\mathrm{CH}_{2}\right)$ and the bands at 1363 and $1347 \mathrm{~cm}^{-1}$ were assigned to $\omega\left(\mathrm{CH}_{2}\right)$, respectively. The new bands at 1091 and $1126 \mathrm{~cm}^{-1}$ appeared after the adsorption of cyclohexanol on $\mathrm{Nb}_{2} \mathrm{O}_{5}$. These bands are assigned to the stretching mode of a $\mathrm{C}-\mathrm{O}$ bond in the alkoxide species on the $\mathrm{Nb}_{2} \mathrm{O}_{5}$, because the formation of the alkoxide species by the adsorption of alcohol is usually accompanied by a shift of the stretching mode of a $\mathrm{C}-\mathrm{O}$ bond to a higher wavenumber [83-85]. Under UV irradiation $(<390 \mathrm{~nm})$, the intensity of the band assigned to $v(\mathrm{C}-\mathrm{O})$ (around $1090 \mathrm{~cm}^{-1}$ ) decreased as the irradiation time increased, whereas the bands assigned to $v(\mathrm{C}=\mathrm{O})(1676$ $\left.\mathrm{cm}^{-1}\right)$ and the symmetric-stretching of the carboxylic acid anion $\left(1554 \mathrm{~cm}^{-1}\right)$ gradually grew. This result indicates that the alkoxide species on $\mathrm{Nb}_{2} \mathrm{O}_{5}$ was excited by photons and oxidized to carbonyl compounds. The carbonyl compounds were formed even under visible light irradiation (> $390 \mathrm{~nm})$.

A broad ESR signal around $g=1.9$ was observed at $123 \mathrm{~K}$, when 1-pentanol was adsorbed on $\mathrm{Nb}_{2} \mathrm{O}_{5}$ under UV-irradiation. This broad signal at $g=1.9$ was assignable to $\mathrm{Nb}^{4+}$ $[86,87]$ and immediately disappeared by the exposure to $\mathrm{O}_{2}$ in the dark, indicating that $\mathrm{Nb}^{4+}$ was oxidized to $\mathrm{Nb}^{5+}$ rapidly even at $123 \mathrm{~K}$. On the other hand, when 1-pentanol was adsorbed on $\mathrm{Nb}_{2} \mathrm{O}_{5}$ under UV-irradiation at 77K, ESR signal $\left(g=2.006, A_{\mathrm{H} 1}=2.0 \mathrm{mT}, A_{\mathrm{H} 2}=\right.$ $4.4 \mathrm{mT}$ ) assigned to alkoxide carbon radical species was observed. These new signals were stable at $77 \mathrm{~K}$ without photo-irradiation, but disappeared at room temperature. The signal did not change in the presence of $\mathrm{O}_{2}$ even under UV-irradiation, indicating that the alkoxide carbon radical species dose not react with $\mathrm{O}_{2}$. 
On the basis of these results, we proposed the reaction mechanism of photo-oxidation of alcohol on $\mathrm{Nb}_{2} \mathrm{O}_{5}$ (Scheme 4) [75-77]; 1) alcohol is adsorbed on $\mathrm{Nb}_{2} \mathrm{O}_{5}$ to form alkoxide species, 2) the photo-formed electron is trapped on $\mathrm{Nb}^{5+}$ to form $\mathrm{Nb}^{4+}$ and positive hole is captured by alkoxide species to convert to active alkoxide carbon radical, 3) the active alkoxide carbon radical is dehydrogenatied to carbonyl compound (the reduction of $\mathrm{Nb}^{5+}$ to $\mathrm{Nb}^{4+}$ takes place simultaneously), 4) the product desorbs, and 5) the reduced $\mathrm{Nb}^{4+}$ sites are re-oxidized by the reaction with $\mathrm{O}_{2}$.

2.2.5. Generation of donor level derived from alcohol and amine adsorbed on $\mathrm{Nb}_{2} \mathrm{O}_{5}$

In order to investigate the formation of a new energy level derived form adsorbed alcohol, DFT calculations were employed. The electronic structure of the model of alkoxide- $\mathrm{Nb}_{2} \mathrm{O}_{5}$ complex was compared to that of $\mathrm{Nb}_{2} \mathrm{O}_{5}$ by DFT calculations. Figure 11A shows the model cluster of the T-phase $\mathrm{Nb}_{2} \mathrm{O}_{5}\left(\mathbf{1} ; \mathrm{Nb}_{12} \mathrm{O}_{43} \mathrm{H}_{26}\right)$ and that of dissociative adsorption of methanol onto T-phase $\mathrm{Nb}_{2} \mathrm{O}_{5}(100)$ surface $\left(2 ; \mathrm{Nb}_{12} \mathrm{O}_{42} \mathrm{H}_{25}\left(\mathrm{OCH}_{3}\right)\right.$ ). In the cluster 2, one terminal hydroxyl group was substituted with methoxy one. The occupied and the virtual orbitals of these model clusters consisted of $\mathrm{O} 2 \mathrm{p}$ orbitals and $\mathrm{Nb} 4 \mathrm{~d}$ orbitals, respectively. Figure 11B shows selected frontier orbitals of $\mathbf{1}$ and $\mathbf{2}$. The cluster $\mathbf{2}$ exhibits quite different electronic state from the cluster 1. Particularly with HOMO and HOMO-1 of 2, O 2p orbitals localize on oxygen atom of the methoxy group. The energy levels of HOMO and HOMO-1 are higher than that of HOMO of $\mathbf{1}$, whereas the energy levels of LUMO and other unoccupied orbitals of $\mathbf{1}$ and $\mathbf{2}$ are almost same (Fig. 12). These results clearly showed that donor levels whose populations are localized on the alkoxide oxygen were generated between the HOMO and LUMO levels of $\mathrm{Nb}_{2} \mathrm{O}_{5}$ by the formation of surface complex (alkoxide- $\mathrm{Nb}_{2} \mathrm{O}_{5}$ ) and that the electron transitions from $\mathrm{O} 2 \mathrm{p}$ donor level derived from the adsorbed alkoxide species to the conduction band of $\mathrm{Nb}_{2} \mathrm{O}_{5}\left(\mathrm{Nb} 4 \mathrm{~d}\right.$ orbitals) had lower energy than those from $\mathrm{O} 2 \mathrm{p}$ of $\mathrm{Nb}_{2} \mathrm{O}_{5}$ 
(the conduction band) to $\mathrm{Nb} 4 \mathrm{~d}$ [77]. Indeed, the electron excitation energies of $\mathbf{1}$ and $\mathbf{2}$ calculated by TD-DFT (time dependent-DFT) revealed that lower energy transition takes place with 2 than with $\mathbf{1}$. Thus, the photo-oxidation of alcohols proceeding by lower-energy light than the band gap of $\mathrm{Nb}_{2} \mathrm{O}_{5}$ can be explained by excitation of the surface complex, i.e., direct electron excitation from $\mathrm{O} 2 \mathrm{p}$ orbital localized on alkoxide oxygen to conduction band of $\mathrm{Nb}_{2} \mathrm{O}_{5}$ consisting of $\mathrm{Nb} 4 \mathrm{~d}$ orbital (Scheme 5).

On the basis of these results, we concluded that the photo-oxidation of alcohol over $\mathrm{Nb}_{2} \mathrm{O}_{5}$ takes place through the direct electron transfer from the $\mathrm{O} 2 \mathrm{p}$ orbital of adsorbed alkoxide species to the conduction band consisting of $\mathrm{Nb} 4 \mathrm{~d}$ orbitals ("in situ doping"). As a result of "in situ doping", the photo-oxidation of alcohol proceeded even under visible light irraidiation. In a analogous way, amine oxidation over $\mathrm{Nb}_{2} \mathrm{O}_{5}$ with visible light may be attributed to a direct electron transfer from a donor level consisting of a N2p orbital derived from adsorbed amide species (Scheme 6) [79]. At first, dissociative adsorption of amine forms an amide (RR'N-Nb) species. The photo-formed electron is trapped on $\mathrm{Nb}^{5+}$ to form $\mathrm{Nb}^{4+}$ and positive hole is captured by amide species to convert to active amide radical. The active amide radical is dehydrogenated to imine compound. Then, photo-formed imine desorbed from $\mathrm{Nb}_{2} \mathrm{O}_{5}$. Finally, the reduced $\mathrm{Nb}^{4+}$ sites are re-oxidized by the reaction with $\mathrm{O}_{2}$. The corresponding primary imine was not detected. However, ammonia and benzaldehyde in addition to $\mathrm{N}$-benzylidene benzylamine were detected, indicating that the hydrolysis of primary imine took place. Moreover, when benzaldehyde was added to benzylamine in the absence of $\mathrm{Nb}_{2} \mathrm{O}_{5}$ under the dark, the condensation of benzaldehyde and benzylamine to $\mathrm{N}$-benzylidene benzylamine immediately and quantitatively proceeded. These results indicate that a rapid dimerization takes place regardless of catalyst and photo-irradiation; the produced primary imine is hydrolyzed to aldehyde and ammonia, followed by condensation of the aldehyde and the primary amine. 


\section{Acceptor level generated by adsorbed molecule}

3.1. Chemical fixation and photocatalytic reduction of carbon dioxide

Carbon dioxide $\left(\mathrm{CO}_{2}\right)$ is regarded as one of the greenhouse effects gases, that cause the global warming by absorption of the infrared ray and enclose it in air [88]. The relationship between the emission of $\mathrm{CO}_{2}$ is still under discussions, however, it is certain that the emission of $\mathrm{CO}_{2}$ should be reduced [89]. Up to now, a number of different ways for the reducing of $\mathrm{CO}_{2}$ emission including strage in the ground and sea, absorption into various functionalized materials, and large scale forestation has been proposed. On the other hand, the transformation of $\mathrm{CO}_{2}$ to harmless and/or valuable chemicals seems to be quite attractive way for the reducing of $\mathrm{CO}_{2}$ emission. However, this is one of the important challenges in chemistry because $\mathrm{CO}_{2}$ is remarkably stable. Therefore, severe reaction conditions of high pressure and/or high temperature are often required.

On the other hand, in photocatalytic reactions the reaction system in the initial stage is activated to have an additional chemical potential by photoirraidiation. Therefore, photocatalysts often permit the reaction which hardly proceeds under the usual condition. There are manu studies that have tried to reduce $\mathrm{CO}_{2}$ under irradiation using several photocatalysts [90-98]. We found that $\mathrm{Rh} / \mathrm{TiO}_{2}, \mathrm{MgO}, \mathrm{ZrO}_{2}$ and $\mathrm{Ga}_{2} \mathrm{O}_{3}$ enable the reduction of $\mathrm{CO}_{2}$ to proceed at room temperature and ambient pressure [99-108]. Here, the detail of the photoreduction of $\mathrm{CO}_{2}$ over $\mathrm{MgO}$ and $\mathrm{ZrO}_{2}$ is described in the following sections.

\subsection{Photoreduction of $\mathrm{CO}_{2}$ on $\mathrm{MgO}$}

\subsubsection{Photoreduciton of $\mathrm{CO}_{2}$ with $\mathrm{H}_{2}$ or $\mathrm{CH}_{4}$ on $\mathrm{MgO}$}

$\mathrm{MgO}$ exhibited photocatalytic activity for the reduction of $\mathrm{CO}_{2}$ to $\mathrm{CO}$ using $\mathrm{H}_{2}$ or $\mathrm{CH}_{4}$ as a reductant $[106,107]$. After $5 \mathrm{~h}$ of photoirradiation using $\mathrm{CH}_{4}$ as a reductant, the amount of 
evolved $\mathrm{CO}$ reached $3.6 \mu \mathrm{mol}$. After $6 \mathrm{~h}$ of photoirradiation using $\mathrm{H}_{2}$, the $\mathrm{CO}$ evolution was $2.9 \mu \mathrm{mol}$. When the reaction was carried out in the dark, without a catalyst or without a reductant $\left(\mathrm{H}_{2}\right.$ or $\left.\mathrm{CH}_{4}\right)$, no $\mathrm{CO}$ was detected, indicating that 1) photo-reduction of $\mathrm{CO}_{2}$ on $\mathrm{MgO}$ was due entirely to a photocatalytic reaction, and that 2) $\mathrm{H}_{2}$ and $\mathrm{CH}_{4}$ were required as a reductant of $\mathrm{CO}_{2}$. Only a small amount of $\mathrm{CO}$ was formed on $\mathrm{MgO}$ by irradiation with a wavelength longer than $290 \mathrm{~nm}$. This indicates that the reaction requires UV light with a wavelength shorter than $290 \mathrm{~nm}$. Since the light source (a $500 \mathrm{~W}$ ultrahigh-pressure mercury lamp) does not supply light with sufficient energy to excite the intrinsic band gap of $\mathrm{MgO}$, the intrinsic band gap excitation of $\mathrm{MgO}$ is not essential in this photoreaction. This fact strongly suggests that electron transfer between $\mathrm{MgO}$ and $\mathrm{CO}_{2}$ is important in this photoreaction.

Figure 13 shows change in the amount of $\mathrm{CO}$ evolution and $\mathrm{CH}_{4}$ consumption over $\mathrm{MgO}$ under photoirradiation. The amount of consumed $\mathrm{CH}_{4}$ was considerably larger than that of evolved $\mathrm{CO}$ up to $8 \mathrm{~h}$ of reaction. The amount of consumed $\mathrm{CH}_{4}$ was not compatible with the $\mathrm{CO}$ evolution stoichiometrically. This suggests that intermediate anchored on the surface of $\mathrm{MgO}$ during the photo-reducition of $\mathrm{CO}_{2}$.

\subsubsection{Surface species on $\mathrm{MgO}$}

Figure 14 shows the dependence of the initial amount of introduced $\mathrm{CO}_{2}$ on the amount of $\mathrm{CO}$ evolved from the photocatalytic reduction and subsequent heat treatment using $\mathrm{CH}_{4}$ as a reductant. No $\mathrm{CO}$ evolution from the photocatalytic reaction was detected until the amount of introduced $\mathrm{CO}_{2}$ reached $66 \mu \mathrm{mol} \cdot \mathrm{g}-\mathrm{MgO}^{-1}$. The $\mathrm{CO}$ evolution increased with increasing the amount of $\mathrm{CO}_{2}$ and then was almost constant above $133 \mu \mathrm{mol} \cdot \mathrm{g}-\mathrm{MgO}^{-1}$, that was consistent with the maximaum amount of chmisorbed $\mathrm{CO}_{2}$ on $\mathrm{MgO}\left(130 \mu \mathrm{mol} \cdot \mathrm{g}-\mathrm{MgO}^{-1}\right)$. On the other hand, the largest $\mathrm{CO}$ evolution due to heat treatment after the photocatalytic reaction was obsserved when the amount of introduced $\mathrm{CO}_{2}$ was $66 \mu \mathrm{mol} \cdot \mathrm{g}-\mathrm{MgO}^{-1}$. When the introduction 
of $\mathrm{CO}_{2}$ was larger than $133 \mu \mathrm{mol} \cdot \mathrm{g}-\mathrm{MgO}^{-1}$, the amount of $\mathrm{CO}_{2}$ had a little influence on the amount of the $\mathrm{CO}$ evolution due to heat treatment. The amount of chemisorbed $\mathrm{CO}_{2}$ was compatible with the minimum amount of introduced $\mathrm{CO}_{2}$ in yielding the maximum $\mathrm{CO}$ evolution due to the photocatalytic reaction $\left(133 \mu \mathrm{mol} \cdot \mathrm{g}-\mathrm{MgO}^{-1}\right)$. The introduction of 66 $\mu \mathrm{mol} \cdot \mathrm{g}-\mathrm{MgO}^{-1}$ of $\mathrm{CO}_{2}$ caused the largest $\mathrm{CO}$ evolution by heat treatment. In addition, the $\mathrm{CO}$ evolution due to the photocatalytic reaction could be detected in the gas phase after the amount of introduced $\mathrm{CO}_{2}$ reached $66 \mu \mathrm{mol} \cdot \mathrm{g}-\mathrm{MgO}^{-1}$. The $\mathrm{CO}$ evolutions due to the photocatalytic reaction and heat treatment were constant after the amount of introduced $\mathrm{CO}_{2}$ reached $133 \mu \mathrm{mol} \cdot \mathrm{g}-\mathrm{MgO}^{-1}$. Interestingly, there were two different thresholds in the photocatalytic reduction of $\mathrm{CO}_{2}$ over $\mathrm{MgO}$. These results suggest that the species produced when the introduced $\mathrm{CO}_{2}$ is below $66 \mu \mathrm{mol} \cdot \mathrm{g}-\mathrm{MgO}^{-1}$ is different from that produced when it is larger than $66 \mu \mathrm{mol} \cdot \mathrm{g}-\mathrm{MgO}^{-1}$. The similar effect of the initial amount of introduced $\mathrm{CO}_{2}$ on the amount of $\mathrm{CO}$ evolved using $\mathrm{H}_{2}$ intead of $\mathrm{CH}_{4}$ [106].

Figures 15 and 16 represent the IR spectra of adsrbed species on $\mathrm{MgO}$ (a) after exposure to $\mathrm{CO}_{2}$ and evacuation, (b) after exposure to $\mathrm{CO}_{2}$ and $\mathrm{H}_{2}$ or $\mathrm{CH}_{4}$ and photoirraidiation, and (c) after evacuation. When $\mathrm{MgO}$ was exposure to $\mathrm{CO}_{2}$, many bands appeared in the region of $1800-2500 \mathrm{~cm}^{-1}$ because of the formation of several caronate species (unidentate, bidentate, and bicarbonate) [83] [109-111]. We investigated the effect of the amount of introduced $\mathrm{CO}_{2}$ on the intensity of bands due to two bidentate carbonates (Fig. 17). Both species were detected when a small amount of $\mathrm{CO}_{2}$ was introduced. Yanagisawa et al. reported that the bands due to species A increased in intensity at $373 \mathrm{~K}$, whereas the bands due to species $\mathrm{B}$ disppeaed [111], indicating that species $\mathrm{A}$ adsorbed strongly on $\mathrm{MgO}$ than species $\mathrm{B}$. The increase in the absorbance of the bands at 1660 and $1310 \mathrm{~cm}^{-1}$ due to species A stopped after

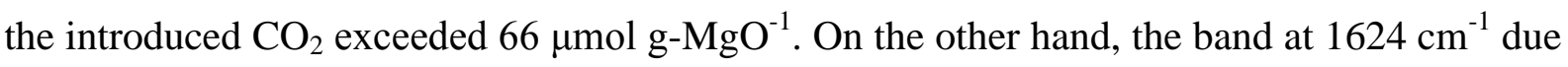
to species B increased when a sufficient amount of $\mathrm{CO}_{2}\left(>66 \mu \mathrm{mol} \mathrm{g}-\mathrm{MgO}^{-1}\right)$ was introduced. 
Based on these resluts combined with the effect of amount of $\mathrm{CO}_{2}$ on the $\mathrm{CO}$ formation, it is conluded that species $\mathrm{A}$, was reduced to a mere intermediate that was inactive for $\mathrm{CO}$ evolution. Above $66 \mu \mathrm{mol} \cdot \mathrm{g}-\mathrm{MgO}^{-1}$ of $\mathrm{CO}_{2}$, species $\mathrm{B}$ was generated instead of species $\mathrm{A}$. It seems that species B was reduced to a surface-active intermediate that can react with $\mathrm{H}_{2}$ or $\mathrm{CH}_{4}$ to produce $\mathrm{CO}$ from $\mathrm{CO}_{2}$.

Figures 15(b) and 16(b) show the IR spectra of $\mathrm{MgO}$ after irradiation in the presence of $\mathrm{H}_{2}$ or $\mathrm{CH}_{4}$. Increase or decrease in intensity and appearance of new bands were observed in the IR spectra in the region of $2900-2700$ and $1800-1250 \mathrm{~cm}^{-1}$. New bands at 2957, 2830, and $2730 \mathrm{~cm}^{-1}$ assigned to a C-H stretching vibration band [112, 113] appeared (the inset in Fig. 6). Since surface carbonates have no $\mathrm{C}-\mathrm{H}$ stretching vibration mode, the appearance of these bands exhibits the formation of a surface species containing a $\mathrm{C}-\mathrm{H}$ bond. The difference IR spectrum of $\mathrm{MgO}$ irradiated in the presence of $\mathrm{H}_{2}$ was similar to that of formaldehyde species adsorbed on $\mathrm{MgO}$ [114]. Therefore, it was concluded that the surface species arising during the photoreaction between $\mathrm{CO}_{2}$ and $\mathrm{H}_{2}$ is a surface bidentate formate. On the other hand, the inset in Fig. 16 shows the subtraction of the IR spectrum of adsorbed species on $\mathrm{MgO}$ in the presence of $\mathrm{CH}_{4}$ before photoirradiation (Fig. 16(a)) from that after photoirradiation (Fig. 16(b)). In the case of using $\mathrm{CH}_{4}$ as a reductant, new bands in the region of 2900-2700 and $1800-1250 \mathrm{~cm}^{-1}$ were observed in addition to the bands due to bidentate formate. These new bands were assaignable to an acetate. Consequently, the species adsorbed on $\mathrm{MgO}$ converts to the surface bidentate acetate as well as the surface bidentate formate as an intermediate in the presence of $\mathrm{CH}_{4}$ under photoirradiation.

\subsubsection{Reactivity of Surface species on $\mathrm{MgO}$}

To investigate the role of the surface bidentate formate and the surface bidentate acetate as an intermediate, we carried out the $\mathrm{CO}_{2}$ photocatalytic reduction over $\mathrm{MgO}$ pretreated with 
$\mathrm{HCHO}$ or $\mathrm{CH}_{3} \mathrm{CHO}$. When $\mathrm{HCHO}$ or $\mathrm{CH}_{3} \mathrm{CHO}$ solely was introduced onto $\mathrm{MgO}$, no $\mathrm{CO}$ was detected even after photoirradiation. $\mathrm{CO}$ was not observed when $\mathrm{MgO}$ was irradiated in the presence of $\mathrm{HCHO}$ in the presence of $\mathrm{H}_{2}$ or $\mathrm{CH}_{4}$. Moreover, $\mathrm{CO}$ was not observed when $\mathrm{MgO}$ was irradiated in the presence of $\mathrm{HCHO}$ or $\mathrm{CH}_{3} \mathrm{CHO}$ in the presence of $\mathrm{CH}_{4}$. However, $\mathrm{CO}$ was evolved when $\mathrm{CO}_{2}$ was introduced to $\mathrm{MgO}$ together with $\mathrm{HCHO}$ or $\mathrm{CH}_{3} \mathrm{CHO}$ under photoirradiation. This reaction did not proceed in the dark. These results indicate that the surface formate or acetate species gives $\mathrm{CO}$ in the presence of $\mathrm{CO}_{2}$ under photoirradiation.

${ }^{13} \mathrm{CO}$ was formed when ${ }^{13} \mathrm{CO}_{2}$ and ${ }^{12} \mathrm{CH}_{4}$ were used as reactants, whereas ${ }^{12} \mathrm{CO}$ was formed when ${ }^{12} \mathrm{CO}_{2}$ and ${ }^{13} \mathrm{CH}_{4}$ were used. This indicates that $\mathrm{CO}$ was derived from $\mathrm{CO}_{2}$. The carbon atom of $\mathrm{CO}_{2}$ was labeled by ${ }^{13} \mathrm{C}$ and the photoreaction between ${ }^{13} \mathrm{CO}_{2}$ and $\mathrm{H}^{12} \mathrm{CHO}$ was carried out. In this case, only ${ }^{13} \mathrm{CO}$ was formed. Therefore, $\mathrm{CO}$ generated was derived from $\mathrm{CO}_{2}$. Therefore, the surface formate does not decompose to yield $\mathrm{CO}$ directly, but acts as a reductant and converts another $\mathrm{CO}_{2}$ molecule to gaseous $\mathrm{CO}$ under photoirradiation.

These results are summarized as follows. Both the bidentate carbonates (species A and B) were generated when $\mathrm{CO}_{2}$ adsorbed on $\mathrm{MgO}$. The formation of species $\mathrm{A}$ took place preferentially until the amount of introduced $\mathrm{CO}_{2}$ reached $\mu$ mol $\bullet \mathrm{g}-\mathrm{MgO}^{-1}$. And then, species $\mathrm{B}$ was formed and $\mathrm{CO}$ was produced in the gas phase. The $\mathrm{CO}$ evolution by the photocatalytic reaction and the heat treatment became constant when the amount of introduced $\mathrm{CO}_{2}$ exceeded the maximaum amount of chmisorbed $\mathrm{CO}_{2}$ on $\mathrm{MgO}\left(130 \mu \mathrm{mol} \cdot \mathrm{g}-\mathrm{MgO}^{-1}\right)$. In conclusion, species A would be connected with only magnesium cation and remain on $\mathrm{MgO}$ as an inactive species because there are excessive base sites of $\mathrm{MgO}$. On the other hand, species $\mathrm{B}$, which was adsorbed by the side-on adsorption-type form, is reduced to a surface bidentate formate or a surface bidentate acetate by $\mathrm{H}_{2}$ or $\mathrm{CH}_{4}$. $\mathrm{CO}$ does not generate from these species. However, these species act as photoactive species on $\mathrm{MgO}$. 


\subsubsection{Photo-activation of $\mathrm{CO}_{2}$ on $\mathrm{MgO}$}

Surface bidentate formate or a surface bidentate acetate contributed to the evolution of CO under photoirradiation. Since $\mathrm{CO}_{2}$ species adsorbed on $\mathrm{MgO}$ was reduced to a surface bidentate formate or a surface bidentate acetate in the presence of $\mathrm{H}_{2}$ or $\mathrm{CH}_{4}$. Therefore, it is expected that the $\mathrm{CO}_{2}$ adsorbed on $\mathrm{MgO}$ would be photoactivated under photoirradiation. Figure 18 shows photoluminescence excitation spectra of $\mathrm{MgO}$. The maximum excitation intensity appeared at $240 \mathrm{~nm}(5.2 \mathrm{eV})$, was assigned to excitation of bulk $\mathrm{MgO}$. The photoluminescence excitation spectra at $240 \mathrm{~nm}$ was remarkably quenched by the introduction of $\mathrm{CO}_{2}$ to $\mathrm{MgO}$, indicating that $\mathrm{CO}_{2}$ interacted with the extrinsic lattice defects. On the other hand, the intensity of the excitation wavelength at $320 \mathrm{~nm}$ increased when $\mathrm{CO}_{2}$ was adsorbed on $\mathrm{MgO}$. These results indicate that there are the two types of photo-excitation processes. One is due to the intrinsic band gap excitation of $\mathrm{MgO}$. It can be thought that the other is due to the direct electron transfer from a new level generated between the HOMO (the valence band) and LUMO (the conduction band) levels of $\mathrm{MgO}$ by the formation of surface complex (bidentate carbonate-MgO) to LUMO or from HOMO to a new level. Figure shows phosphorescence emmision spectra of $\mathrm{MgO}$ adsorbed $\mathrm{CO}_{2}$. The braod band observed ap at 350-600 nm was quenched by the introduction of $\mathrm{H}_{2}$ or $\mathrm{CH}_{4}$. This indicates that the photoactive species derived from the adsorbed $\mathrm{CO}_{2}$ interacted with $\mathrm{H}_{2}$ and $\mathrm{CH}_{4}$.

EPR signals of $\mathrm{CO}_{2}^{-}$and $\mathrm{CO}_{3}{ }^{-}$radicals as photoactivated species on $\mathrm{MgO}$ were clearly observed after the photoirradiation of $\mathrm{MgO}$ adsorbed $\mathrm{MgO}$. These signals were highly stable in the dark after photoirradiation. However, the photoactivated species on $\mathrm{MgO}\left(\mathrm{CO}_{2}^{-}\right.$and $\mathrm{CO}_{3}{ }^{-}$radicals) reacted with $\mathrm{H}_{2}$ or $\mathrm{CH}_{4}$. When $\mathrm{H}_{2}$ was introduced to $\mathrm{MgO}$ in the dark, the signals derived from the $\mathrm{CO}_{2}^{-}$and $\mathrm{CO}_{3}{ }^{-}$radicals disappeared in short order. In addition, the $\mathrm{CO}_{2}{ }^{-}$radical species vanished more quickly than the $\mathrm{CO}_{3}{ }^{-}$radical species. We concluded that in this reaction, the $\mathrm{CO}_{2}^{-}$radical is reduced by $\mathrm{H}_{2}$ to formate or acetate rather than the $\mathrm{CO}_{3}{ }^{-}$ 
radical.

\subsubsection{Mechanism of photo-reduction of $\mathrm{CO}_{2}$ on $\mathrm{MgO}$}

Based on above rsults, we propose the follwing mechanism of the $\mathrm{CO}_{2}$ photocatalytic reduction in the presence of $\mathrm{H}_{2}$ or $\mathrm{CH}_{4}$ as a reductant (Scheme 7); Two bidentate carbonates (species $\mathrm{A}$ and $\mathrm{B}$ ) are generated on $\mathrm{MgO}$ in introducing $\mathrm{CO}_{2}$. The bidentate carbonates are activated under photoirradiation and are converted to a $\mathrm{CO}^{2-}$ or $\mathrm{CO}^{3-}$ radical. Anion species $\left(\mathrm{CO}^{2-}\right.$ and $\mathrm{CO}^{3-}$ radical) was generated by the irradiation with a wavelength longer than 290 $\mathrm{nm}$, indicating that the intrinsic band gap excitation of $\mathrm{MgO}$ is not essential in this photoactivation step. Therefore, it seems that the direct electron transfer from HOMO to a new level generated between the HOMO (the valence band) and LUMO (the conduction band) levels of $\mathrm{MgO}$ by the formation of surface complex (bidentate carbonate-MgO). In this case, a new level derived from surface complex (bidentate carbonate-MgO) acts as "an acceptor level" (Scheme 8). The $\mathrm{CO}^{3-}$ radical derived from species A was transformed to a bicarbonate, which is inactive for the $\mathrm{CO}_{2}$ photocatalytic reduction. On the other hand, the $\mathrm{CO}^{2-}$ radical species derived from species $\mathrm{B}$ is reduced to a surface bidentate formate or acetate in the presence of $\mathrm{H}_{2}$ or $\mathrm{CH}_{4}$. The surface bidentate formate and acetate are highly stable on $\mathrm{MgO}$ and reduce $\mathrm{CO}_{2}$ in the gas phase to $\mathrm{CO}$ under photoirradiation.

\subsection{Photoreduction of $\mathrm{CO}_{2}$ on $\mathrm{ZrO}_{2}$}

$\mathrm{ZrO}_{2}$ was found to exhibit activity for the photoreduction of $\mathrm{CO}_{2}$ with $\mathrm{H}_{2}$ or $\mathrm{CH}_{4}$ [101-105]. We repored that the mechanism of photoreduction of $\mathrm{CO}_{2}$ on $\mathrm{ZrO}_{2}$ is essentailly same to that on $\mathrm{MgO}$. Bidentate carbonate was formed on $\mathrm{ZrO}_{2}$ by the introduction $\mathrm{CO}_{2}$. Adsorbed $\mathrm{CO}_{2}$ (bidentate carbonate) was photoexcited to a triplet state; a part of the $\mathrm{CO}_{2}$ in the triplet state is deactivated and returns to the ground state upon releasing an emission at $440 \mathrm{~nm}$, while the 
rest is stabilized as a $\mathrm{CO}^{2-}$ anion radical. The wavelength of light effective for the photoreduction of $\mathrm{CO}_{2}$ was longrt than that at which $\mathrm{ZrO}_{2}$ absorbs $(<250 \mathrm{~nm})$. Therefore, the intrinsic band gap excitation of $\mathrm{ZrO}_{2}$ is not essential in this photoactivation step and a new level generated between the HOMO and LUMO levels of $\mathrm{ZrO}_{2}$ by the formation of surface complex (bidentate carbonate- $\mathrm{ZrO}_{2}$ ). In this case, a new level acts as "an acceptor level" as well as the photoreduction of $\mathrm{CO}_{2}$ on $\mathrm{MgO}$. The $\mathrm{CO}^{2-}$ anion radical reacts with $\mathrm{H}_{2}$ in the gas phase to produce the surface formate spiceis. And then, the surface formate reduces $\mathrm{CO}_{2}$ in the gas phase to $\mathrm{CO}$ under photoirradiation.

\section{Coclusions}

The direct electron transition between the donor/acceptor level generated by adsorbed molecules and the conduction/valence band for photo-illuminated semiconductor type metal oxide ("in situ doping") is demonstrated.

In the case of photo-SCR over $\mathrm{TiO}_{2}$, a new donor level from adsorbed $\mathrm{NH}_{2}$ species was generated between the valence band (O 2p) and the conduction band (Ti 3d) by the adsorption of $\mathrm{NH}_{3}$ on $\mathrm{TiO}_{2}$. The direct electron transition from donor level to the conduction band took place to form $\mathrm{NH}_{2}$ radical species by visible light irradiation and $\mathrm{NO}$ in the gas phase attacked the $\mathrm{NH}_{2}$ radical to form $\mathrm{NH}_{2} \mathrm{NO}$ (nitrosamide) intermediate (Eley-Rideal type mechanism). And then, the $\mathrm{NH}_{2} \mathrm{NO}$ species is decomposed to $\mathrm{N}_{2}$ and $\mathrm{H}_{2} \mathrm{O}$. As a result, the photo-SCR proceeded even under visible light irradiation.

Photo-oxidation of alcohols and amines with molecular oxygen selectively proceeds on $\mathrm{Nb}_{2} \mathrm{O}_{5}$. As well as the adsorbed $\mathrm{NH}_{3}$ on $\mathrm{TiO}_{2}$, a new electron donor level was generated between the valence band $(\mathrm{O} 2 \mathrm{p})$ and the conduction band $(\mathrm{Nb} 4 \mathrm{~d})$ by the adsorption of alcohol or amine on $\mathrm{Nb}_{2} \mathrm{O}_{5}$. The direct electron transition from donor level derived from 
alkoxide species to the conduction band took place to form alkyl carbon radical species by photo-irradiation. Therefore, the photo-formed electron is trapped on $\mathrm{Nb}^{5+}$ to form $\mathrm{Nb}^{4+}$ and positive hole is captured by alkoxide species on $\mathrm{Nb}_{2} \mathrm{O}_{5}$ to convert to alkyl carbon radical. The formed alkyl carbon radical was immediately dehydrogenated to carbonyl compound. In the case of the photo-oxidation of amines, in an analogous way, the direct electron transition from donor level derived from amide species to the conduction band took place to form amide radical species by photo-irradiation.

On the orher hand, in the cases of the photo-reduction of $\mathrm{CO}_{2}$ to $\mathrm{CO}$ on $\mathrm{MgO}$ or $\mathrm{ZrO}_{2}$, a new electron acceptor level was generated between the valence band and the conduction band by the adsorption of $\mathrm{CO}_{2}$ on $\mathrm{MgO}$ or $\mathrm{ZrO}_{2}$. Both $\mathrm{MgO}$ and $\mathrm{ZrO}_{2}$ exhibit photocatalytic activity for the reduction of $\mathrm{CO}_{2}$ to $\mathrm{CO}$ using $\mathrm{H}_{2}$ or $\mathrm{CH}_{4}$ as a reductant. Surface bidentate formate or surface bidentate acetate contributed to the evolution of $\mathrm{CO}$ under photoirradiation. The bidentate carbonates are activated under photoirradiation and are converted to a $\mathrm{CO}^{2-}$ or $\mathrm{CO}^{3-}$ radical. Anion species $\left(\mathrm{CO}^{2-}\right.$ and $\mathrm{CO}^{3-}$ radical $)$ was generated by the irradiation with a wavelength longer than $290 \mathrm{~nm}$, which implies that the intrinsic band gap excitation of $\mathrm{MgO}$ is not essential in this photoactivation step. The direct electron transfer from HOMO to a new level generated between the valence band and the conduction band levels of $\mathrm{MgO}$ by the formation of surface complex (bidentate carbonate- $\mathrm{MgO}$ ). In this case, a new level derived from surface complex acts as "an acceptor level".

As mentioned above, the direct electron transition between the donor/acceptor level generated by adsorbed molecules and the conduction/valence band for photo-illuminated semiconductor-type metal oxide ("in situ doping") resulsts in a redshift of effective wavelength and "in situ doping" gives us attractive ways for the removing the limit of band gap energy, and the utilization of visible light. 


\section{Acknowledgements}

This study was partially supported by and Grants-in-Aid for Scientific Research on Priority Area (No. 10734036, "Molecular Nano Dynamics" and No. 20037038, "Chemistry of Concerto Catalysis), and Scientific Research (B) (No. 19360365). K. T. was supported by the Program for Improvement of Research Environment for Young Researchers from Special Coordination Funds for Promoting Science and Technology (SCF) commissioned by the MEXT of Japan. The authors thank Dr. Yoshiumi Kohno, Dr. Seiji Yamazoe, Mr. Tai Ohuchi, Mr. Toshiaki Miyatake, Mr. Shinya Furukawa, Miss. Ayaka Tamura, and Mr. Yasuhiro Ohno at Kyoto University for the collaboration to this study. 


\section{References}

[1] M.A. Fox, C.C. Chen, J. Am. Chem. Soc. 103 (1981) 6757-6759.

[2] K.M. Sancier, S.R. Morrison, Surf. Sci. 83 (1979) 29-44.

[3] R.I. Bickley, G. Munuera, F.S. Stone, J. Catal. 31 (1973) 398-407.

[4] V.S. Zakharenko, A.E. Cherkashin, N.P. Keier, G.F. Gerasimova, Kinet. Catal. 16 (1975) 142-148.

[5] V.S. Zakharenko, A.E. Cherkashin, N.P. Keier, S.V. Koshcheev, Kinet. Catal. 16 (1975) 149-154.

[6] W.R. Murphy, T.F. Veerkamp, T.W. Leland, J. Catal. 43 (1976) 304-321.

[7] M. Formenti, F. Juillet, Meriaude.P, S.J. Teichner, Bulletin De La Societe Chimique De France (1972) 69-\&.

[8] K. Maeda, K. Domen, J. Phys. Chem. C. 111 (2007) 7851-7861.

[9] K. Maeda, K. Domen, Chem. Mater.. 22 (2010) 612-623.

[10] R. Abe, M. Higashi, K. Domen, ChemSusChem. 4 (2011) 228-237.

[11] A. Kudo, Y. Miseki, Chem. Soc. Rev. 38 (2009) 253-278.

[12] S. Sato, Chem. Phys. Lett. 123 (1986) 126-128.

[13] R. Asahi, T. Morikawa, T. Ohwaki, K. Aoki, Y. Taga, Science. 293 (2001) 269-271.

[14] H.M. Luo, T. Takata, Y.G. Lee, J.F. Zhao, K. Domen, Y.S. Yan, Chem. Mater.. 16 (2004) 846-849.

[15] M. Miyauchi, A.K. Nakajima, T. Watanabe, K. Hashimoto, Chem. Mater.. 14 (2002) 4714-4720.

[16] H. Yu, H. Irie, Y. Shimodaira, Y. Hosogi, Y. Kuroda, M. Miyauchi, K. Hashimoto, J. Phys. Chem. C. 114 (2010) 16481-16487.

[17] S. Cho, Chem. Eng. Prog. 90 (1994) 39-45.

[18] P. Forzatti, L. Lietti, HETEROGEN CHEM REV. 3 (1996) 33-51.

[19] F. Nakajima, Syokubai. 32 (1990) 236.

[20] S. Wood, Chem. Eng. Prog. 90 (1994) 32-38.

[21] V. Parvulescu, P. Grange, B. Delmon, Catal. Today. 46 (1998) 233-316.

[22] T. Tanaka, K. Teramura, T. Funabiki, Phys. Chem. Chem. Phys. 2 (2000) 2681-2682.

[23] T. Tanaka, K. Teramura, K. Arakaki, T. Funabiki, Chem. Commun. (2002) $2742-2743$.

[24] K. Teramura, T. Tanaka, T. Funabiki, Langmuir. 19 (2003) 1209-1214.

[25] K. Teramura, T. Tanaka, T. Funabiki, Chem. Lett. 32 (2003) 1184-1185.

[26] K. Teramura, T. Tanaka, M. Kani, T. Hosokawa, T. Funabiki, J. Mol. Catal. A-Chem. 208 (2004) 299-305.

[27] K. Teramura, T. Tanaka, S. Yamazoe, K. Arakaki, T. Funabiki, Appl. Catal. B-Environ. 53 (2004) 29-36.

[28] S. Yamazoe, T. Okumura, K. Teramura, T. Tanaka, Catal. Today. 111 (2006) 266-270.

[29] S. Yamazoe, T. Okumura, Y. Hitomi, T. Shishido, T. Tanaka, J. Phys. Chem. C. 111 (2007) 11077-11085.

[30] S. Yamazoe, T. Okumura, T. Tanaka, Catal. Today. 120 (2007) 220-225.

[31] S. Yamazoe, K. Teramura, Y. Hitomi, T. Shishido, T. Tanaka, J. Phys. Chem. C. 111 (2007) 14189-14197.

[32] S. Yamazoe, Y. Hitomi, T. Shishido, T. Tanaka, Appl. Catal. B-Environ. 82 (2008) $67-76$.

[33] S. Yamazoe, Y. Hitomi, T. Shishido, T. Tanaka, J. Phys. Chem. C. 112 (2008) 6869-6879.

[34] S. Yamazoe, Y. Masutani, K. Teramura, Y. Hitomi, T. Shishido, T. Tanaka, Appl. Catal. B-Environ. 83 (2008) 123-130.

[35] T. Tanaka, K. Teramura, T. Yamamoto, S. Takenaka, S. Yoshida, T. Funabiki, J. Photoch. Photobio. A. 148 (2002) 277-281.

[36] R. Asahi, T. Morikawa, Y. Taga, Abstr. Pap. Am. Chem. Soc. 222 (2001) U633-U633. 
[37] G. Ramis, L. Yi, G. Busca, M. Turco, E. Kotur, R.J. Willey, J. Catal. 157 (1995) 523-535.

[38] M.C. Kung, H.H. Kung, Catal. Rev.-Sci. Eng. 27 (1985) 425-460.

[39] C.C. Chuang, J.S. Shiu, J.L. Lin, Phys. Chem. Chem. Phys. 2 (2000) 2629-2633.

[40] E. Ito, Y.J. Mergler, B.E. Nieuwenhuys, H.P.A. Calis, H. vanBekkum, C.M. vandenBleek, J. Chem. Soc.-Faraday Trans. 92 (1996) 1799-1806.

[41] P. Meriaudeau, M. Che, C.K. Jorgensen, Chem. Phys. Lett. 5 (1970) 131-133.

[42] C. Hauser, Z. Angew. Math. Phys. 22 (1971) 783.

[43] R.F. Howe, M. Gratzel, J. Phys. Chem. 89 (1985) 4495-4499.

[44] D.C. Hurum, A.G. Agrios, K.A. Gray, T. Rajh, M.C. Thurnauer, J. Phys. Chem. B. 107 (2003) 4545-4549.

[45] S.N. Foner, E.L. Cochran, V.A. Bowers, C.K. Jen, Phys. Rev. Lett. 1 (1958) 91-94.

[46] E.F. Vansant, J.H. Lunsford, J. Phys. Chem. 76 (1972) 2716-\&.

[47] S. Nagai, Bull. Chem. Soc. Jpn. 46 (1973) 1144-1148.

[48] N. Shimamoto, K. Hatano, T. Katsu, Y. Fujita, Bull. Chem. Soc. Jpn. 48 (1975) $18-21$.

[49] S. Ikeda, N. Sugiyama, B. Pal, G. Marci, L. Palmisano, H. Noguchi, K. Uosaki, B. Ohtani, Phys. Chem. Chem. Phys. 3 (2001) 267-273.

[50] S. Ikeda, N. Sugiyama, S. Murakami, H. Kominami, Y. Kera, H. Noguchi, K. Uosaki, T. Torimoto, B. Ohtani, Phys. Chem. Chem. Phys. 5 (2003) 778-783.

[51] R.A. Rheldon, J.K. Kochi, Metal-Catalyzed Oxidations of Organic Compounds (Academic Press, New York, 1981).

[52] M. Hudlicky, Oxidations in Organic Chemistry (American Chemical Society, Washington DC, 1990).

[53] C.L. Hill, Advances in Oxygenated Process (JAI, London, 1998).

[54] S.I. Murahashi, Angew. Chem. Int. Ed. 34 (1995) 2443-2465.

[55] R.C. Larock, Comprehensive Organic Transformations (VCH, New York, 1989).

[56] K.C. Nicolaou, C.J.N. Mathison, T. Montagnon, Angew. Chem.-Int. Edit. 42 (2003) 4077-4082.

[57] K.C. Nicolaou, C.J.N. Mathison, T. Montagnon, J. Am. Chem. Soc. 126 (2004) $5192-5201$.

[58] T. Mukaiyama, A. Kawana, Y. Fukuda, J. Matsuo, Chem. Lett. (2001) 390-391.

[59] R.A. Sheldon, I. Arends, A. Dijksman, Catal. Today. 57 (2000) 157-166.

[60] T. Mallat, A. Baiker, Chem. Rev. 104 (2004) 3037-3058.

[61] K. Yamaguchi, N. Mizuno, Angew. Chem.-Int. Edit. 41 (2002) 4538-+.

[62] K. Yamaguchi, K. Mori, T. Mizugaki, K. Ebitani, K. Kaneda, J. Am. Chem. Soc. 122 (2000) 7144-7145.

[63] K. Yamaguchi, N. Mizuno, Angew. Chem.-Int. Edit. 42 (2003) 1480-1483.

[64] K. Mori, K. Yamaguchi, T. Mizugaki, K. Ebitani, K. Kaneda, Chem. Commun. (2001) 461-462.

[65] U.R. Pillai, E. Sahle-Demessie, J. Catal. 211 (2002) 434-444.

[66] J. Chen, D.F. Ollis, W.H. Rulkens, H. Bruning, Water Research. 33 (1999) 661-668.

[67] J.L. Falconer, K.A. Magrini-Bair, J. Catal. 179 (1998) 171-178.

[68] D.S. Muggli, K.H. Lowery, J.L. Falconer, J. Catal. 180 (1998) 111-122.

[69] Q. Wang, M. Zhang, C. C., W. Ma, J. Zhao, Angew. Chem. Int. Ed. 49 (2010) 7976-7979.

[70] M. Zhang, Q. Wang, C. Chen, Z. L., W. Ma, J. Zhao, Angew. Chem. Int. Ed. 48 (2010) 6081-6084.

[71] X. Lang, H. Ji, C. Chen, W. Ma, J. Zhao, Angew. Chem. Int. Ed. 50 (2011) 3934-3937.

[72] F. Su, S.C. Mathew, G. Lipner, X. Fu, M. Antonietti, S. Blechert, X. Wang, J. Am. Chem. Soc. 132 (2010) 16299-16301.

[73] F. Su, S.C. Mathew, L. Moehlmann, M. Antonietti, X. Wang, S. Blechert, Angew. Chem.-Int. Edit. 50 (2011) 657-660.

[74] D. Tsukamoto, M. Ikeda, Y. Shiraishi, T. Hara, N. Ichikuni, S. Tanaka, T. Hirai, Chem.-Eur. J. 17 (2011) 9816-9824.

[75] T. Ohuchi, T. Miyatake, Y. Hitomi, T. Tanaka, Catal. Today. 120 (2007) 233-239. 
[76] T. Shishido, T. Miyatake, K. Teramura, Y. Hitomi, H. Yamashita, T. Tanaka, J. Phys. Chem. C. 113 (2009) 18713-18718.

[77] S. Furukawa, Y. Ohno, T. Shishido, K. Teramura, T. Tanaka, ChemPhysChem in press.

[78] S. Furukawa, A. Tamura, T. Shishido, K. Teramura, T. Tanaka, Appl. Catal. B-Environ. in press.

[79] S. Furukawa, Y. Ohno, T. Shishido, K. Teramura, T. Tanaka, ACS Catalysis in press.

[80] S.-I. Murahashi, Y. Okano, H. Sato, T. Nakae, N. Komiya, Synlett (2007) $1675-1678$.

[81] M.-H. So, Y. Liu, C.-M. Ho, C.-M. Che, Chem. Asian Journal. 4 (2009) 1551-1561.

[82] Y. Maeda, T. Nishimura, S. Uemura, Bull. Chem. Soc. Jpn. 76 (2003) 2399-2403.

[83] L.H. Little, A.V. Kiselev, V.I. Lygin, Infrared Spectra of Adsorbed Species (Academic Press Inc., London, 1966).

[84] G. Socrates, Infrared Characteristic Group Frequencies: Table and Charts (Wiley, New York, 1994).

[85] V.Z. Fridman, A.A. Davydov, K. Titievsky, J. Catal. 222 (2004) 545-557.

[86] M. Sugantha, U.V. Varadaraju, G.V.S. Rao, J. Solid State Chem. 111 (1994) 33-40.

[87] C. Verissimo, F.M.S. Garrido, O.L. Alves, P. Calle, A. MartinezJuarez, J.E. Iglesias, J.M. Rojo, Solid State Ionics. 100 (1997) 127-134.

[88] J. Legget, Global Warming (Oxford University Press, New York, 1990).

[89] W.S. Broecker, Nature. 328 (1987) 123-126.

[90] H. Fujiwara, H. Hosokawa, K. Murakoshi, Y. Wada, S. Yanagida, T. Okada, H. Kobayashi, J. Phys. Chem. B. 101 (1997) 8270-8278.

[91] K.R. Thampi, J. Kiwi, M. Gratzel, Nature. 327 (1987) 506-508.

[92] T. Inoue, A. Fujishima, S. Konishi, K. Honda, Nature. 277 (1979) 637-638.

[93] B. Aurianblajeni, M. Halmann, J. Manassen, Solar Energy. 25 (1980) 165-170.

[94] K. Sayama, H. Arakawa, J. Photoch. Photobio. A. 94 (1996) 67-76.

[95] K. Sayama, H. Arakawa, J. Phys. Chem. 97 (1993) 531-533.

[96] K. Iizuka, Y. Kojima, A. Kudo, Shokubai. 51 (2009) 228-233.

[97] O. Ishitani, M.W. George, T. Ibusuki, F.P.A. Johnson, K. Koike, K. Nozaki, C.J. Pac, J.J. Turner, J.R. Westwell, Inorg. Chem. 33 (1994) $4712-4717$.

[98] H. Hori, J. Ishihara, K. Koike, K. Takeuchi, T. Ibusuki, O. Ishitani, J. Photoch. Photobio. A. 120 (1999) 119-124.

[99] Y. Kohno, H. Hayashi, S. Takenaka, T. Tanaka, T. Funabiki, S. Yoshida, J. Photoch. Photobio. A. 126 (1999) 117-123.

[100] Y. Kohno, T. Yamamoto, T. Tanaka, T. Funabiki, J. Mol. Catal. A-Chem. 175 (2001) 173-178.

[101] Y. Kohno, T. Tanaka, T. Funabiki, S. Yoshida, Chem. Commun. (1997) 841-842.

[102] Y. Kohno, T. Tanaka, T. Funabiki, S. Yoshida, Chem. Lett. (1997) 993-994.

[103] Y. Kohno, T. Tanaka, T. Funabiki, S. Yoshida, J. Chem. Soc.-Faraday Trans. 94 (1998) 1875-1880.

[104] Y. Kohno, T. Tanaka, T. Funabiki, S. Yoshida, Phys. Chem. Chem. Phys. 2 (2000) 2635-2639.

[105] Y. Kohno, T. Tanaka, T. Funabiki, S. Yoshida, Phys. Chem. Chem. Phys. 2 (2000) 5302-5307.

[106] Y. Kohno, H. Ishikawa, T. Tanaka, T. Funabiki, S. Yoshida, Phys. Chem. Chem. Phys. 3 (2001) 1108-1113.

[107] K. Teramura, T. Tanaka, H. Ishikawa, Y. Kohno, T. Funabiki, J. Phys. Chem. B. 108 (2004) 346-354.

[108] K. Teramura, H. Tsuneoka, T. Shishido, T. Tanaka, Chem. Phys. Lett. 467 (2008) 191-194.

[109] Y. Fukuda, K. Tanabe, Bull. Chem. Soc. Jpn. 46 (1973) 1616-1619.

[110] H. Tsuji, T. Shishido, A. Okamura, Y.Z. Gao, H. Hattori, H. Kita, J. Chem. Soc.-Faraday Trans. 90 (1994) 803-807.

[111] Y. Yanagisawa, K. Takaoka, S. Yamabe, T. Ito, J. Phys. Chem. 99 (1995) 3704-3710.

[112] G. Busca, J. Lamotte, J.C. Lavalley, V. Lorenzelli, J. Am. Chem. Soc. 109 (1987) 
5197-5202.

[113] O.Y. Feng, J.N. Kondo, K. Maruya, K. Domen, J. Chem. Soc.-Faraday Trans. 93 (1997) 169-174.

[114] G.W. Wang, H. Hattori, J. Chem. Soc.-Faraday Trans. I. 80 (1984) 1039-1047. 
Table 1 Aerobic oxidation of various amines to corresponding imines using $\mathrm{Nb}_{2} \mathrm{O}_{5}{ }^{a}$

\begin{tabular}{|c|c|c|c|c|c|}
\hline Entry & Substrate & Product & $\mathrm{T} / \mathrm{h}$ & Conv. $(\%)$ & Sel. $(\%)^{b}$ \\
\hline 1 & & & 50 & $>99$ & 97 \\
\hline $1^{\prime}$ & & & 24 & 21 & 97 \\
\hline & & & & $0^{c}$ & $--^{c}$ \\
\hline 2 & & & 24 & $>99$ & 99 \\
\hline $2^{\prime}$ & & & 24 & 29 & 94 \\
\hline 3 & & & 38 & $>99$ & 95 \\
\hline 3 ' & & & 24 & 19 & 94 \\
\hline 4 & & & 45 & $>99$ & 98 \\
\hline $4^{\prime}$ & & & 24 & 12 & 94 \\
\hline 5 & & & 51 & $>99$ & 96 \\
\hline 6 & & & 27 & $>99$ & 95 \\
\hline 6' & OMe & Me & 24 & 30 & 95 \\
\hline 7 & & & 29 & $>99$ & 94 \\
\hline 7' & & & 24 & 16 & 95 \\
\hline 8 & & & 24 & $>99$ & $61(14)^{d}$ \\
\hline 9 & & & 20 & 97 & $71(23)$ \\
\hline 9' & & & 24 & 16 & $70(29)$ \\
\hline 10 & & & 48 & 15 & $63(21)$ \\
\hline $10^{\prime}$ & & & 24 & 2.5 & $86(9)$ \\
\hline 11 & & & 15 & 82 & $92(5)$ \\
\hline 11 ' & & & 24 & 47 & $91(5)$ \\
\hline 12 & & & 24 & 30 & $88(7)$ \\
\hline $12^{\prime}$ & & & 24 & 13 & $89(8)$ \\
\hline 13 & & & 11 & $>99$ & $92(5)^{e}$ \\
\hline $13^{\prime}$ & & & 24 & 47 & $85(6)^{e}$ \\
\hline 14 & & & 48 & 43 & $70(4,20)^{f, g}$ \\
\hline $14^{\prime}$ & & & 24 & 4.2 & $84(8)^{g}$ \\
\hline
\end{tabular}



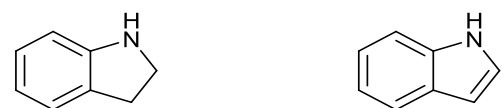

${ }^{a}$ Reaction condition: $\mathrm{Nb}_{2} \mathrm{O}_{5}(100 \mathrm{mg})$, substrate $(5 \mathrm{mmol})$, benzene as a solvent $(10 \mathrm{ml}), \lambda>300 \mathrm{~nm}$ (entries $\left.1-15\right)$ or $\lambda>390 \mathrm{~nm}$ (entries $\left.1^{\prime}-15^{\prime}\right)$, oxygen pressure $(1 \mathrm{~atm}){ }^{b}$ Selectivities to corresponding imines. Figures in parentheses show selectivities to benzaldehyde. ${ }^{c}$ Without catalyst. Selectivities to ${ }^{d} N, N$-dibutylformamide, ${ }^{e}$ isoquinoline $,{ }^{f} 3,4$-dihydroquinoline, ${ }^{g}$ 3,4-dihydroquinoline-1(2H)-carbaldehyde, ${ }^{h}$ indoline-1-carbaldehyde and ${ }^{i}$ 10,11-dihydro-5H-dibenzo $[b$,f $]$ azepine, respectively. 


\section{Figure captions}

Figure 1. Time course of $\mathrm{N}_{2}$ (circle) and $\mathrm{N}_{2} \mathrm{O}$ (triangle) in the photo-SCR with $\mathrm{NH}_{3}$ over $\mathrm{TiO}_{2}$ JRC-TIO-11, Reaction condition; GHSV $=8000 \mathrm{~h}^{-1}$, NO: 1000ppm, $\mathrm{NH}_{3}: 1000 \mathrm{ppm}$, $\mathrm{O}_{2}: 2 \%$, Ar balance

Figure 2. Action spectrum of photo-SCR (dot) and UV-Vis spectrum of JRC-TIO-11 (liner); reaction condition of action spectrum: $\mathrm{NH}_{3}: 1000 \mathrm{ppm}$, NO: 1000ppm, $\mathrm{O}_{2}: 2 \%$, flow rate: 100 $\mathrm{ml} / \mathrm{min}$.

Figure 3. FT-IR spectra of adsorbed species on $\mathrm{TiO}_{2}$ in the photo-SCR with $\mathrm{NH}_{3}$. (a) after introduction of $\mathrm{NH}_{3}$, (b) after evacuation, (c) after introduction of $\mathrm{NO}$ in the dark, (d) under photo irradiation for $10 \mathrm{~min}$, (e) for $30 \mathrm{~min}$, (f) for $60 \mathrm{~min}$, and (g) for $120 \mathrm{~min}$.

Figure 4. ESR spectra of $\mathrm{TiO}_{2}$ (a) after pretreatment, (b) after introduction of $\mathrm{NH}_{3}$ in the dark, (c) under photo irradiation and (d) after introduction of NO in the dark.

Figure 5. Models of (a) $\mathrm{Ti}_{7} \mathrm{O}_{27} \mathrm{H}_{26}$ fixed cluster and the optimized geometries, (b) $\mathrm{NH}_{3}$-adsorbed $\mathrm{Ti}_{7} \mathrm{O}_{27} \mathrm{H}_{26}$ fixed cluster, and (c) $\mathrm{NH}_{3}$ dissociative adsorbed $\mathrm{Ti}_{7} \mathrm{O}_{27} \mathrm{H}_{26}$ fixed cluster.

Figure 6. Energy levels around HOMO and LUMO for (a) $\mathrm{Ti}_{7} \mathrm{O}_{27} \mathrm{H}_{26}$, (b) $\mathrm{NH}_{3}$-adsorbed $\mathrm{Ti}_{7} \mathrm{O}_{27} \mathrm{H}_{26}$, and (c) $\mathrm{NH}_{3}$ dissociative adsorbed $\mathrm{Ti}_{7} \mathrm{O}_{27} \mathrm{H}_{26}$.

Figure 7. Selected molecular orbitals of $\mathrm{NH}_{3}$ dissociative adsorbed $\mathrm{Ti}_{7} \mathrm{O}_{27} \mathrm{H}_{26}$ fixed cluster.

Figure 8. Action spectrum of photooxidation of 1-penanol (dot) and UV-Vis spectrum of $\mathrm{Nb}_{2} \mathrm{O}_{5}$ (liner). Reaction conditions of the action spectrum were as follows: 1-pentanol (10 ml), $\mathrm{Nb}_{2} \mathrm{O}_{5}(100 \mathrm{mg}), 323 \mathrm{~K}$, under $0.1 \mathrm{MPa}$ of $\mathrm{O}_{2}, \mathrm{O}_{2}$ flow rate $\left(2 \mathrm{~cm}^{3} \mathrm{~min}^{-1}\right)$. Action spectrum of 1-pentanol photooxidation over $\mathrm{Cu} / \mathrm{Nb}_{2} \mathrm{O}_{5}, \mathrm{UV}$-Vis spectra of $\mathrm{Cu} / \mathrm{Nb}_{2} \mathrm{O}_{5}$ and 1-pentanol adsorbed on $\mathrm{Cu} / \mathrm{Nb}_{2} \mathrm{O}_{5}$, and difference spectrum between them.

Figure 9. FT-IR spectra of adsorbed species on $\mathrm{Nb}_{2} \mathrm{O}_{5}$ in the photo-reaction of adsorbed cyclohexanol with $\mathrm{O}_{2}$. (a) cyclohexanol was exposed to $\mathrm{Nb}_{2} \mathrm{O}_{5}$ for $1 \mathrm{~h}$ and evacuated for $2 \mathrm{~h}$, (b) under UV irradiation for 1 , (c) 5 , (d) 7 , (e) 10 , (f) 15 and (g) 30 min. $\mathrm{Nb}_{2} \mathrm{O}_{5}$ was 
evacuated at $773 \mathrm{~K}$ for $1 \mathrm{~h}$ and oxidized at $773 \mathrm{~K}$ with $10.7 \mathrm{kPa}$ of $\mathrm{O}_{2}$ and then evacuated at $773 \mathrm{~K}$ for $1 \mathrm{~h}$ before FT-IR measurements.

Figure 10. A) Model clusters of $\mathrm{T}-\mathrm{Nb}_{2} \mathrm{O}_{5} ; \mathrm{Nb}_{12} \mathrm{O}_{43} \mathrm{H}_{26}$ (1) and alkoxide adsorbed on T- $\mathrm{Nb}_{2} \mathrm{O}_{5}(100) ; \mathrm{Nb}_{12} \mathrm{O}_{42} \mathrm{H}_{25}\left(\mathrm{OCH}_{3}\right)$ (2). (B) Graphical illustrations of LUMO, HOMO and HOMO of 1 and 2.

Figure 11. Energy diagram of the frontier orbitals of $\mathbf{1}$ and $\mathbf{2}$.

Figure 12. Time dependence of the amount of $\mathrm{CO}$ evolution $(\mathbf{O})$ and $\mathrm{CH}_{4}$ consumption $(\mathbf{\Delta})$ over $\mathrm{MgO}$ under photoirradiation.

Figure 13. Dependence of the amount of CO evolved by the photo-catalytic reaction and by the heat treatment after photocatalytic reaction $(\mathbf{A})$ on the initial amount of introduced $\mathrm{CO}_{2}$.

Figure 14. Difference IR spectra of the adsorbed species on $\mathrm{MgO}$ (a) after introduction of $3.9 \mathrm{kPa}$ of $\mathrm{CO}_{2}$ and evacuation, (b) after introduction of $5.1 \mathrm{kPa}$ of $\mathrm{H}_{2}$ and under photoirradiation for $18 \mathrm{~h}$, and (c) after evacuation. The inset illustrates the difference spectrum between (a) and (b) in the region of $1800-1250 \mathrm{~cm}^{-1}$, indicating the spectrum of adsorbate.

Figure 15. Difference IR spectra of the adsorbed species on $\mathrm{MgO}$ (a) after introduction of $3.9 \mathrm{kPa}$ of $\mathrm{CO}_{2}$ and evacuation, (b) after introduction of $5.2 \mathrm{kPa}$ of $\mathrm{CH}_{4}$ and under photoirradiation for $18 \mathrm{~h}$, and (c) after evacuation. The inset illustrates the difference spectrum between (a) and (b) in the region of 1800-1250 $\mathrm{cm}^{-1}$, indicating the spectrum of adsorbate.

Figure 16. Two bidentate species on $\mathrm{MgO}$

Figure 17. Phosphorescence excitation spectra of $\mathrm{MgO}$ (a) after pretreatment, (b) after

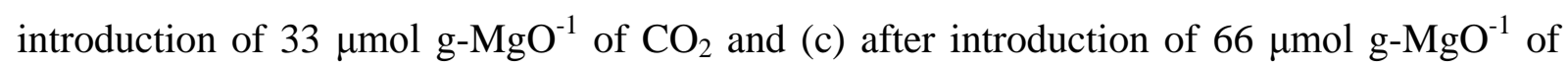
$\mathrm{CO}_{2}$.

Scheme 1. Model of reaction, charge separation, and recombination over photocatalyst

Scheme 2. Reaction mechanism of photo-SCR with $\mathrm{NH}_{3}$ over $\mathrm{TiO}_{2}$ 
Scheme 3. Formation mechanism of $\mathrm{NH}_{2}$ radical over $\mathrm{TiO}_{2}$

Scheme 4. Reaction mechanism of alcohol photooxidation with molecular oxygen over $\mathrm{Nb}_{2} \mathrm{O}_{5}$

Scheme 5. Formation mechanism of alkyl carbon radical over $\mathrm{Nb}_{2} \mathrm{O}_{5}$

Scheme 6. Formation mechanism of amide radical radical over $\mathrm{Nb}_{2} \mathrm{O}_{5}$

Scheme 7. Reaction mechanism of $\mathrm{CO}_{2}$ photo-reduction with $\mathrm{H}_{2}$ or $\mathrm{CH}_{4}$ over $\mathrm{MgO}$

Scheme 8. Formation mechanism of $\mathrm{CO}_{2}{ }^{-}$or $\mathrm{CO}_{3}{ }^{-}$radical radical over $\mathrm{MgO}$

Table 1. Aerobic oxidation of various amines to corresponding imines using $\mathrm{Nb}_{2} \mathrm{O}_{5}$. 